\title{
LOS ESTUDIOS CRÍTICOS EN ADMINISTRACIÓN: ORIGEN, EVOLUCIÓN Y POSIBILIDADES DE APORTE AL DESARROLLO DEL CAMPO DE LOS ESTUDIOS ORGANIZACIONALES EN AMÉRICA LATINA*
}

\author{
MAURICIO SANABRIA***, JUAN JAVIER SAAVEDRA MAYORGA*** \& ALI SMIDA***** \\ UNIVERSIDAD DEL ROSARIO (COLOMBIA) - UNIVERSIDAD DE CAEN (FRANCIA)
}

Recibido/ Received/ Recebido: 17/03/2014 - Aceptado/ Accepted / Aprovado: 12/08/2014

\begin{abstract}
Resumen
Haciendo eco al llamado de destacados autores latinoamericanos a observar y a dar continuidad a sus trabajos, y considerando el creciente interés dentro de los estudios organizacionales, este artículo hace una revisión del campo de los Estudios Críticos en Administración (ECA) o Critical Management Studies (CMS). El artículo muestra sus orígenes, su evolución y su estado actual, señala algunas de sus limitaciones en lo relacionado con nuestro contexto, y propone una serie de consideraciones para el futuro de los estudios organizacionales en Latinoamérica.
\end{abstract}

Palabras clave: Estudios críticos en administración, Reflexividad, América Latina, Estudios organizacionales, Educación e investigación en administración.

Artículo de reflexión que contiene parte de los resultados del trabajo de investigación presentado por Mauricio Sanabria (2014) como tesis para obtener el título de Doctor en Ciencias de Gestión de la Université de Caen Basse-Normandie, titulado Réévaluation de l'approche cognitive du changement stratégique. Une étude des mutations des facultés de management colombiennes (2007-2012). Pertenece al proyecto de investigación "Desafiando los supuestos básicos de la perspectiva cognitiva del cambio estratégico. Un estudio del inicio de las mutaciones de las Facultades de Administración en Colombia", financiado por la Universidad del Rosario y el gobierno de Francia.

** Ph. D. en Sciences de Gestion, Universidad de Caen (Francia). D.U. (Master 2e année recherche) en Sciences de Gestion, Universidad de Rouen (Francia). Magíster en Administración y Administrador de Empresas, Universidad Nacional de Colombia. Profesor de la Escuela de Administración de la Universidad del Rosario. Miembro del Grupo de Investigación en Perdurabilidad Empresarial (GIPE), línea de investigación en estrategia. Editor de la Revista Universidad \& Empresa (U\&E). Correo electrónico: mauricio.sanabria@ urosario.edu.co. Dirección postal: Universidad del Rosario, sede complementaria: Cll. 200, entre la Autopista Norte y la Carrera 7 , Módulo B, Bogotá (Colombia).

**** Ph. D. en Sciences de Gestion, Universidad de Caen (Francia). D.U. (Master 2e année recherche) en Sciences de Gestion, Universidad de Rouen (Francia). Magíster en Administración y Administrador de Empresas, Universidad Nacional de Colombia. Profesor de la Escuela de Administración de la Universidad del Rosario. Miembro del Grupo de Investigación en Perdurabilidad Empresarial (GIPE), línea de investigación en Liderazgo. Correo electrónico: juan.saavedra@urosario.edu.co.

***** Ph. D. troisième cycle en Analyse et Gestion des Organisations. Troisième cycle en Physique Nucléaire. Doctor de Estado en Sciences de Gestion. Doctor en Pharmacie, Universidad de Caen (Francia). Profesor de Universidades, Universidad Paris 13, Sorbonne Paris Cité. Presidente de la Association Internationale et Interdisciplinaire de la Décision (A2ID). Director del grupo CR2S-Management. Investigador del grupo CEPN CNRS. Correo electrónico: alismida@aol.com. 


\title{
CRITICAL STUDIES IN ADMINISTRATION: ORIGIN, EVOLUTION AND POTENTIAL CONTRIBUTION TO THE FIELD DEVELOPMENT OF ORGANIZATIONAL STUDIES IN LATIN AMERICA
}

\begin{abstract}
Following the call of prominent Latin American authors to observe and to give continuity to their works, and considering their increasing interest about organizational studies, this article made a review of the field of critical studies in administration (ECA) or Critical Management Studies (CMS). The article shows its origins, evolution and current state, points out some of its limitations in relationship to our context, and proposes a number of considerations for the future of organizational studies in Latin America.

Keywords: Critical studies in administration, Reflexivity, Latin America, Organizational studies, Education and research in administration.

\section{OS ESTUDOS CRÍTICOS EM ADMINISTRAÇÃO: ORIGEM, EVOLUÇÃO E POSSIBILIDADES DE CONTRIBUIÇÃO AO DESENVOLVIMENTO DO CAMPO DOS ESTUDOS ORGANIZACIONAIS NA AMÉRICA LATINA}

\section{Resumo}

\begin{abstract}
Fazendo eco ao chamado de destacados autores latino americanos a observá-los e a dar continuidade a seus trabalhos, e considerando seu crescente interesse dentro dos estudos organizacionais, este artigo faz uma revisão do campo dos Estudos Críticos em Administração (ECA) ou Critical Management Studies (*CMS). O artigo mostra suas origens, sua evolução e seu estado atual; indica algumas de suas limitações no relacionado com nosso contexto; e propõe uma série de considerações para o futuro dos estudos organizacionais na América Latina.
\end{abstract}

Palavras chave: Estudos críticos em administração, Reflexividade, América Latina, Estudos organizacionais, Educação e pesquisa em administração.

Sanabria, M., Saavedra, J. \& Smida, A. (2015). Los estudios críticos en administración: origen, evolución y posibilidades de aporte al desarrollo del campo de los estudios organizacionales en América Latina. En: En: Revista de la Facultad de Ciencias Económicas de la Universidad Militar Nueva Granada. rev.fac.cienc.econ, XXIII (1).

JEL: M10, M19.

\section{Introducción}

Los Estudios Críticos en Administración (ECA) -o Critical Management Studies (CMS), la sigla que, por ser la más popular, es utilizada en adelante en este texto- constituyen actualmente un campo am- plio y dinámico, un campo que plantea una mirada renovada a los fenómenos organizacionales. Aunque cuestionan las prácticas hegemónicas e institucionalizadas existentes en el discurso que ha dado forma a los estudios organizacionales (Alvesson \& Willmott, 2011; Alvesson, Bridgman \& Willmott, 2009b), los 
CMS parecen haber contribuido a la reproducción, al menos, de dos de ellas (Tietze \& Dick, 2013), a saber: i) la publicación de trabajos principalmente en inglés, y ii) la realización de investigaciones sobre la base de condiciones históricas, sociales, culturales, políticas y económicas muy específicas, condiciones propias de los países desarrollados.

La proposición fundamental de esta investigación es que estas prácticas, que no necesariamente son deliberadas, sino que hacen parte de los mecanismos de reproducción del propio campo, han afectado la subjetividad y la identidad de un importante número de académicos en América Latina. Han creado en ellos una condición de subordinación, dependencia y aislamiento que ha dificultado su vinculación y su aporte al desarrollo global del campo.

Este artículo, provisto de una perspectiva crítica, se une a otros que han intentado hacer accesible el discurso alternativo de los CMS al mundo hispanohablante (Saavedra, 2009; Fernández, 2007; Herrero, 2012) y a otros más que han buscado desarrollar, desde hace casi tres décadas y principalmente desde el contexto mexicano, una perspectiva particular, latinoamericana, de los CMS (Ibarra, 1991, 2006a, 2006c, 2008a, 2008b; Ibarra \& Montaño, 1985). En este trabajo se hace una revisión a ese discurso y se da cuenta de sus orígenes y evolución, de su grado de institucionalización, de las tensiones que lo atraviesan, de su estado actual y de las limitaciones que tiene para nuestro contexto. Finalmente, se identifican algunas de sus principales tendencias y se plantean ciertas consideraciones en relación con el futuro de los estudios organizacionales en Latinoamérica.

El texto se estructura en tres secciones: i) fundamentos, orígenes y principales aproximaciones de los CMS; ii) evolución y estado actual del campo; y ii) tendencias, limitaciones y consideraciones para el futuro de los estudios organizacionales en Latinoamérica.

\section{Fundamentos, orígenes y principales aproximaciones}

Los Estudios Críticos en Administración (ECA) -o CMS- son 'estudios' porque procuran desarrollar nuevas comprensiones acerca de la administración a través del trabajo investigativo y son 'críticos' porque tienen una intención deliberada y explícita de cuestionar elementos inmersos en la tradición del campo que la ha estudiado y en las relaciones de dominación vinculadas con él (Alvesson, Bridgman \& Willmott, 2009a). Su interés es el de eliminar o reducir la represión, las restricciones y el sufrimiento relacionados con la actividad administrativa en el contexto organizacional (Alvesson, 2008).

Los CMS se sustentan en un supuesto fundamental según el cual el campo de la administración, en sus actividades académicas, investigativas y prácticas, favorece a algunos grupos o élites a expensas de otros y reproduce los intereses sociales y los valores culturales dominantes. Esta inequidad interesada impide la emancipación de los individuos y es signo de que algo anda mal en el campo, algo que debe ser cambiado (Alvesson et al., 2009a, 7; Alvesson \& Willmott, 1995, 86; Fournier \& Grey, 2000, 16).

Para actuar frente a este supuesto, para cambiar lo que está mal, los CMS han planteado una 'definición de trabajo' según la cual este discurso procura:

- El cuestionamiento crítico de ideologías, instituciones, intereses, e identidades (las cuatro I), que se consideran (a) dominantes, (b) perjudiciales y (c) poco cuestionadas.

- A través de negaciones, deconstrucciones, revoicing o des-familiarizaciones.

- Con el propósito de inspirar una reforma social en el presunto interés de la mayoría y/o de los no privilegiados, así como la emancipación y/o resistencia a ideologías, instituciones e identidades que tienden a poner a las personas en un estado no reflexivo frente a ideas, intenciones y prácticas reproducidas -tradicionalmente-.

- Con algún grado de valoración de las restricciones que el trabajo y las situaciones de la vida imponen a las personas (incluyendo a los administradores) en el mundo organizacional contemporáneo, i.e. la de que el legítimo propósito 
de las organizaciones es la producción de bienes y servicios (Alvesson, 2008, 18) ${ }^{1}$.

A partir de este supuesto fundamental y de esa definición de trabajo, los CMS tratan de cuestionar dos consideraciones simplificadoras, pero ampliamente aceptadas al interior de la corriente dominante ( $m a-$ instream) en el campo de la administración:

- [Que] las organizaciones son adecuadamente representadas como instrumentos (imperfectamente) racionales para lograr metas compartidas y/o como medios para satisfacer las necesidades de las personas a través de la producción de bienes y servicios (Alvesson et al., 2009a, 7).

- $\quad$ Que las] compañías y otras organizaciones son instituciones que trabajan para 'el bien común', cuyos resultados consisten en hacer mejor las cosas para los consumidores, los empleados, los propietarios y el público en general. Las estructuras y las prácticas organizacionales son consideradas como funcionales para la realización de los objetivos organizacionales, los cuales sirven a los diferentes stakeholders (Alvesson, 2008, 13).

Para dar fundamento a la crítica que hacen de estas y de otras consideraciones básicas de la corriente dominante, los CMS se alimentan de elementos de diversas fuentes. Desde el campo de la sociología, toman como antecedentes trabajos como el de Bendix (2001), quien estudió las relaciones de subordinación de los trabajadores respecto a los empresarios en cuatro contextos: Estados Unidos, Inglaterra, Rusia y Alemania Oriental. Se consideran igualmente como antecedentes de los CMS los trabajos de John Child (2011), quien en su tesis de doctorado en la Universidad de Cambridge hizo una mirada crítica a la evolución del pensamiento administrativo en Gran Bretaña y resaltó el papel que en ella tuvieron la ciencia social y la ideología.

El trabajo de Anthony (1977) es también reconocido como un antecedente de los CMS, en particular por su análisis sobre la forma en que se construyen las ideologías sobre el trabajo y el modo en que ellas definen los supuestos que hacen los individuos con relación al mismo. Asimismo, es considerada como una fuente importante para el discurso el trabajo de Clegg \& Dunkerley (1980), el cual, acercándose a una perspectiva marxista, promueve la idea de que las organizaciones son mecanismos de control y señala la necesidad de fundamentar el análisis organizacional en una mirada histórica y bien informada.

Se destaca igualmente el influjo de la Escuela de Fráncfort (Assoun, 2012; Durand, 2012). A este respecto se consideran como influencias importantes, por ejemplo, los trabajos de Max Horkheimer -Director del Instituto de Investigación Social (Institut für Sozialforschung - IfS) de la Universidad Goethe de Fráncfort del Meno (Goethe Universität Frankfurt am Main)-, en particular por su crítica a la razón instrumental (Horkheimer, 2002) y por su llamado a desarrollar una mirada crítica a los llamados empleados white-collar (Alvesson et al., 2009a, 23), entre los que él ubicaba a algunos administradores. En general, las fuentes de las que se nutren los CMS, provenientes de la teoría crítica (Ingram, 2010; Schrift, 2010), son más amplias y variadas (Boltanski, 2009; Bronner \& Kellner, 1989; Scherer, 2009; Tyson, 2006).

Existe una importante variedad de otras fuentes de las que los autores vinculados a este discurso toman múltiples elementos de acuerdo con Shenhav (2003, 203), Fournier \& Grey (2000) y otros investigadores (Alvesson, 2008; Alvesson et al., 2009a; Kelemen \& Rumens, 2008), los CMS se han nutrido de fuentes tan diversas como el posmodernismo (Boje, Gephart \& Thatchenkery, 1996; Burrell, 1988, 1994; Clegg, 1990; Cooper \& Burrell, 1988; Grey, 1996; Hancock \& Tyler, 2001); el posestructuralismo (Campbell, 2009; Williams, 2005) así como, en relación este último, el deconstruccionismo (McQuillan, 2001; McQuillan \& Willis, 2010) y, de manera más amplia, la llamada French Theory (Cusset, 2005). Se han alimentado también del neo-marxismo (Braverman,

1 En Alvesson \& Ashcraft $(2009,63)$ hay algunas pequeñas variaciones con respecto a la presentación de estos elementos, No obstante, ellas no modifican en el fondo sino en la forma los planteamientos aquí transcritos. Por esta razón se ha preservado la formulación inicial. 


\section{LOS ESTUDIOS CRIITICOS EN ADMINISTRACIÓN: ORIGEN, EVOLUCIÓN Y POSIBILIDADES DE APORTE AL DESARROLLO DEL CAMPO DE LOS ESTUDIOS ORGANIZACIONALES EN AMÉRICA LATINA}

1998; Clegg \& Dunkerley, 1980; Edwards, 1979; Marglin, 1974); los elementos intra-paradigmáticos (Locke, 1996); el feminismo (Calás \& Smircich, 2006); los estudios culturales (Mattelart \& Neveu, 2008; Miller, 2001); los estudios poscoloniales (Jack \& Westwood, 2009; Prasad, 2003a, 2012), el ambientalismo (Banerjee, 2003) y el psicoanálisis (Gabriel, 1999).

Al interior de esta gran variedad de fuentes se destacan: i) la teoría del proceso de trabajo (labor process theory) (Thompson \& O'Doherty, 2009), la cual se inspira en el trabajo de Braverman (1998); ii) la obra de Max Weber (Burrell, 1999; Durepos, Mills \& Weatherbee, 2012; Jennings, Schulz, Patient, Gravel \& Ke, 2005; Kalinowski, 2009; Lounsbury \& Carberry, 2005; Westwood \& Clegg, 2003; Willmott,
2009); y iii) la obra de Michel Foucault, en particular sus reflexiones sobre el rol de la crítica, sobre el poder y su relación con el conocimiento, sobre la sociedad disciplinar y sobre el método de investigación en ciencias sociales (Saavedra, Sanabria \& Smida, 2013; Burrell, 1988; Granjon, 2009; Hatchuel, Pezet, Starkey \& Lenay, 2005; McKinlay \& Starkey, 1998; Rowlinson \& Carter, 2002).

Una síntesis de las principales aproximaciones existentes en los CMS se presenta en la Tabla 1.

\section{Evolución y estado actual}

Los CMS son, como se observa, un campo pluralista, diverso y multidisciplinario que incorpora "un amplio rango de perspectivas" (Alvesson et al.,

Tabla 1. Principales aproximaciones existentes en los $\mathrm{CMS}^{2}$

\begin{tabular}{|c|c|c|c|}
\hline No. & Aproximación & Descripción & Trabajos representativos \\
\hline 1 & $\begin{array}{l}\text { Deconstruccionista } \\
\text { crítica }\end{array}$ & $\begin{array}{l}\text { Vincula las ideas de Jacques Derrida con una agenda política (como } \\
\text { la del feminismo). }\end{array}$ & Calás \& Smircich (1991); Martin (1990). \\
\hline 2 & Foucaultiana & $\begin{array}{l}\text { Enfatiza la relación conocimiento/poder en diferentes campos de la } \\
\text { administración. }\end{array}$ & $\begin{array}{l}\text { Granjon (2009); Knights (1992); Knights \& } \\
\text { Morgan (1991); Townley (1993). }\end{array}$ \\
\hline 3 & Existencialista & $\begin{array}{l}\text { Estudia la subjetividad y cómo las acciones de poder fomentan la } \\
\text { aceptación y la sumisión, aun cuando siempre hay un espacio para } \\
\text { la incertidumbre, la ansiedad y la resistencia. }\end{array}$ & Collinson (2003); Knights \& Willmott (1989). \\
\hline 4 & \multirow{2}{*}{ Teórica crítica } & $\begin{array}{l}\text { Se soporta en la Escuela de Fráncfort, en particular en Jürgen Haber- } \\
\text { mas, enfatizando el ideal y la posibilidad de la emancipación. }\end{array}$ & $\begin{array}{l}\text { Alvesson \& Willmott (1996, 2003); Forester } \\
\text { (2003); Willmott (2003). }\end{array}$ \\
\hline 5 & & Se inspira también, en algunos casos, en el posmodernismo. & Alvesson \& Deetz (2000); Deetz (1992). \\
\hline 6 & Interpretativista crítica & $\begin{array}{l}\text { Trabaja con un enfoque etnográfico, en el cual el interés por la cultu- } \\
\text { ra y el significado tienen un sesgo crítico. }\end{array}$ & Jackall (1988); Kunda (1992); Watson (1994). \\
\hline 7 & $\begin{array}{l}\text { De los estudios de } \\
\quad \text { género }\end{array}$ & $\begin{array}{l}\text { Enfatiza las experiencias de las mujeres y/o las formas de domina- } \\
\text { ción de ideas culturales sobre la masculinidad. Incluye tanto a los } \\
\text { 'feministas' como a los 'masculinistas'. }\end{array}$ & $\begin{array}{l}\text { Alvesson \& Billing (2009); Calás \& Smircich } \\
\text { (2006); Collinson \& Hearn (1996). }\end{array}$ \\
\hline 8 & Weberiana de izquierda & $\begin{array}{l}\text { Estudia los desarrollos, las ventajas y las desventajas de las formas } \\
\text { burocráticas. Evalúa críticamente las formas opresivas y restrictivas } \\
\text { de jerarquía, la división del trabajo y las rutinas, pero también hace } \\
\text { lo mismo con algunas alternativas presumiblemente radicales y pro- } \\
\text { gresistas como los llamados a las post-burocracias. }\end{array}$ & Adler (1999); Perrow (1986); Sennett (1998). \\
\hline 9 & Del proceso de trabajo & $\begin{array}{l}\text { Aunque cada vez con una mirada menos marxista, estudian crítica- } \\
\text { mente el trabajo en las organizaciones y las relaciones entre emplea- } \\
\text { dor y empleado. }\end{array}$ & $\begin{array}{l}\text { Ackroyd \& Thompson (1999); Karlsson } \\
\text { (2012). }\end{array}$ \\
\hline
\end{tabular}

2 Fuente: Elaboración propia a partir de Alvesson $(2008,16)$. 
2009a, 5). Este hecho representa para algunos un lado positivo y una fortaleza (Alvesson et al., 2009a; Cunliffe, 2008), pero, para otros, entraña dificultades tales como la de identificar cuál aproximación o trabajo es "crítico" y puede inscribirse en los CMS y cuál no lo es (Fournier \& Grey, 2000).

De hecho, al interior de este campo, por la pluralidad y diversidad que lo caracteriza, existe un debate entre considerar, por un lado, la unificación de las múltiples visiones en una mirada convergente que le ofrezca una mayor identidad y coherencia o, por otro, la conservación de la pluralidad y la variedad que lo caracterizan, aunque evitando caer en el extremo de considerar que todo vale (Alvesson et al., 2009a).

La amplia diversidad de los CMS tiene, sin embargo, un importante sustento en la tradición europea $y$ en el desarrollo de las ciencias humanas y sociales propio de este contexto. De hecho, los CMS nacen en la tradición europea de los estudios organizacionales (Sanabria, Saavedra \& Smida, 2014a). Esta tradición empezó a desarrollarse de manera tardía con relación a la estadounidense, como resultado de la mayor dificultad que significó para Europa, con relación a los Estados Unidos, el proceso de recuperación tras la Segunda Guerra Mundial (Augier \& March, 2011).

Por esta razón, la tradición europea de los estudios organizacionales, de la que se alimentan los CMS, empezó a desarrollarse esencialmente en las décadas de 1970 y 1980, un par de decenios después del momento en que comenzó a hacerlo la tradición norteamericana. Como resultado del contexto sociocultural en el que se originó, esta tradición tuvo algunas características distintas de las que identificaron a la norteamericana, la cual se considera en la actualidad como la corriente dominante en el campo de la administración. Clegg \& Dunkerley (1977a, 2) afirmaron al respecto, en ese contexto histórico, lo siguiente:

"De manera complementaria, y algunas veces en oposición, a los desarrollos y sugerencias que emanan de la tradición del 'Administrative Science Quarterly', el es- tudio de las organizaciones ha progresado en Europa. Está emergiendo una tradición europea distintiva. Asuntos metodológicos, teóricos y críticos que una vez parecieron estar condenados al silencio, despiertan de nuevo, son renovados y discutidos. Mucha de esta discusión se ha centrado en la crítica desarrollada actualmente por los miembros del 'groupe théorique' del European Group for Organizational Studies (EGOS)"

En efecto, el Zeitgeist que caracterizó la emergencia de la perspectiva europea de los estudios organizacionales fue distinto al que un par de décadas antes animó la consolidación de la tradición norteamericana (Augier \& March, 2011). Para la constitución de este nuevo clima cultural fueron fundamentales los movimientos de protesta propios de las décadas de 1960 y 1970. Ellos condujeron al establecimiento de una nueva atmósfera intelectual en las universidades europeas, que, entre otras características, se oponía a la hegemonía norteamericana y a la mirada cuantitativa y matemática de la ciencia, y apoyaba lo femenino, la retórica, la historia, la crítica, las contraculturas, el posestructuralismo, el posmodernismo y el constructivismo social. Una atmósfera en la que "Adam Smith y Max Weber fueron desplazados por Michel Foucault y Anthony Giddens" (March, 2007, 14).

En efecto, las tradiciones estadounidense y europea de los estudios organizacionales vivieron procesos de desarrollo y siguieron rutas y perspectivas diferentes, siendo la perspectiva europea la que principalmente ha alimentado a los CMS. Entre 1945 y 1970 las escuelas estadounidenses de formación en administración tuvieron que reaccionar al llamado de 'cientifización' del campo que provenía, entre otros, de los influyentes estudios (Audet \& Déry, 2000; De Rond \& Miller, 2005; Khurana, 2007) patrocinados por la Ford Foundation (Gordon \& Howell, 1959) y por la Carnegie Foundation (Khurana, 2007; Pierson, 1959) sobre la educación en el campo de la administración.

La respuesta condujo a una estrecha vinculación de la tradición norteamericana con los postulados positivistas (Audet \& Déry, 2000), con una tradición filo- 
sófica 'mecanicista' (Starbuck, 2003, 160-162) y con el método hipotético-deductivo (De Rond \& Miller, 2005) como forma básica de aproximación a la realidad en el marco de la actividad investigativa. Se privilegió la cuantificación, la estadística multivariada -ya anclada en la ciencia social americana (Camic \& Xie, 1994; Schminke \& Mitchell, 2003)-, el empirismo, el rigor metodológico y el uso de encuestas a gran escala. Todo ello, con el ánimo de generalizar, prescribir y obtener una utilidad práctica del conocimiento producido por la investigación (Augier, March \& Ni Sullivan, 2005; Bort \& Schiller-Merkens, 2011; Clegg \& Bailey, 2008; Mowday, 1997).

Marsden \& Townley $(1999,409)$ identificaron este fenómeno como el desarrollo de una "ciencia normal de la organización". De acuerdo con estos autores, en la década de 1970 emergió una crítica sistemática a esa concepción y con ella una "contra ciencia de la organización" (Marsden \& Townley, 1999, 413). Un movimiento que, aunque tuvo un correlato en Norteamérica a través de la obra de Weick (1969), se desarrolló esencialmente en Europa a partir, entre otros, de los trabajos de David Silverman (1968, 1970), a quien suele atribuírsele un papel fundamental en el surgimiento de este movimiento alternativo (Clegg \& Bailey, 2008).

La bifurcación que se plantea entre estas posiciones da lugar a la que Westwood \& Clegg $(2003,11)$ denominaron "la más profunda fisura en el discurso de los estudios organizacionales hoy". Una fisura que abrió el espacio, al interior de la "contra ciencia de la organización", para toda una gama de elementos alternativos de los cuales se han nutrido los CMS. Entre estos elementos se destacan, más específicamente, los siguientes (Clegg \& Bailey, 2008; Czarniawska, 1999; Czarniawska \& Sevón, 1996):

- El interpretativismo y la fenomenología.

- El constructivismo social.

- La revalorización del rol del 'significado' como un aspecto definitorio de la realidad social y de la acción de las personas.

- La teoría crítica.
- El posestructuralismo y el posmodernismo: el énfasis en la complejidad del mundo, la relativización de la verdad absoluta en función de los intereses de los individuos, la interrelación conocimiento-poder y la interpretación espaciotemporal de la información.

- El marxismo y las discusiones en torno a la clase, el proceso de trabajo, la desigualdad de las relaciones de producción, el historicismo, las estructuras sociales y el poder.

- El feminismo y las cuestiones de género, raza y etnicidad.

- Las discusiones relacionadas con la identidad, el cuerpo, el alma, la mente, el lenguaje y el discurso (presentes en textos, conversaciones, marcas y otras representaciones).

- La relevancia de la subjetividad en el contexto organizacional y en la propia investigación (incluyendo, entre otros, temas como la reflexividad, los prejuicios, la política y los valores).

- Los estudios culturales.

- La teoría poscolonialista.

- El deconstruccionismo.

El campo de los estudios organizacionales, los CMS y la tradición europea que se fue conformando en ese contexto, se nutrieron entonces del trabajo de diversos sociólogos que encontraron espacio para el desarrollo de su pensamiento al interior de las escuelas de formación en administración (Taskin, 2011). De hecho, Alvesson $(2008,19)$ define a un autor estándar de los CMS como un "sociólogo radical que no pudo tener un trabajo en un departamento de sociología o que se dio cuenta de que los recursos y las oportunidades de promoción son mejores en administración que en una disciplina académica 'real"3.

En esta atmósfera intelectual y sociocultural, ampliamente difundida en el entorno europeo, se abrió el espacio para planteamientos de diversos autores que hoy sobresalen en el campo de los estudios organizacionales (y algunos de ellos también en los CMS). Son reconocidos en este contexto los nombres de "Mats Alvesson, Nils Brunsson, John Child, Stewart Clegg, Barbara Czarniawska, Lars Engwall, Erhard

3 Ver también a Rowlinson \& Hassard (2011). 
Friedberg, Anthony Hopwood, Håkon Håkonsson, Alfred Kieser, Cornelius J. Lammers, Bruno Latour, Niklas Luhmann, Renate Mayntz, Johan P. Olsen, Andrew Pettigrew, Jean-Claude Thoenig" (March, 2007, 13).

En ese contexto (Burrell, 2009), se procura que al interior del campo de los estudios organizacionales y de los CMS las discusiones acerca de los procesos de poder y los intereses de los participantes en la configuración de las organizaciones ocupen un lugar más protagónico. Se cuestiona el supuesto normativo -aceptado durante la década de 1960 y el inicio de la década de 1970- de que "un incremento en la productividad de una organización automáticamente conduce a un mejoramiento de las condiciones sociales" (Scherer, 2003, 323). Conceptos como "poder, control e inequidad", más cercanos a una mirada crítica (Fournier \& Grey, 2000, 17), desplazan a otros tales como "eficiencia, efectividad y rentabilidad".

El espíritu que animó el desarrollo de los estudios organizacionales en Europa, a partir de la tradición de las ciencias sociales y humanas propio de ese contexto (Nauert, 2006), procuró reconocer en los individuos su condición de seres humanos y no concebirlos en términos eficientistas (i.e., performativos), es decir como instrumentos que deben ser útiles al logro de los objetivos organizacionales (Saavedra, 2006). Consideró al individuo como un ser humano integral que no deja de serlo por el hecho de estar inmerso en un contexto organizacional. Privilegió, entonces, la comprensión de lo "humano organizacional".

Esta última, aunque aparentemente sutil, es una diferencia importante frente a la tradición norteamericana de los estudios organizacionales: en la tradición europea no se hace énfasis en comprender al ser humano con el fin de mejorar o maximizar su eficiencia, sino en comprenderlo en tanto ser integral inmerso en un contexto organizacional (Vino, 1996). De ahí que se abra un espacio para la realización de trabajos que procuran comprender la condición humana, vista desde múltiples facetas, así como las relaciones que los individuos establecen en el contexto organizativo desde esa condición.
Es en este contexto en el que se configuran los CMS (Fournier \& Grey, 2000; Grey \& Willmott, 2005a). Su denominación proviene en esencia de la compilación de trabajos hecha por Alvesson \& Willmott (1992b) titulada, justamente, Critical Management Studies (Grey \& Willmott, 2005a; Tadajewski, Maclaran, Parsons \& Parker, 2011a). Esto aunque en realidad, para ese entonces, ya existían algunos trabajos imbuidos del espíritu crítico que animaría el campo (Alvesson, 1987; Alvesson \& Willmott, 1992a; Grey \& Willmott, 2005b, 17-56; Perrow, 1972; Wood \& Kelly, 1978).

Entre esos trabajos se destacan al menos dos compilaciones, a saber: i) en Europa, la obra Critical Issues in Organizations, editada por Clegg \& Dunkerley (1977b); y ii) en Latinoamérica, las dos ediciones coordinadas por Ibarra \& Montaño $(1985,1991)$ de la obra Ensayos críticos para el estudio de las organizaciones en México. El rótulo que da inicio formal al discurso, en cualquier caso, ha tenido importantes efectos en materia de "mercadeo" de los CMS y ha sido importante para su difusión en el mundo (Alvesson et al., 2009a, 5).

$\mathrm{Al}$ interior de los CMS, por la tradición de la que son herederos, se han desarrollado trabajos relacionados con temas transversales como el poder (Clegg, 1989; Clegg \& Haugaard, 2012; Fleming \& Spicer, 2007; Hardy, 1995; Knights \& Willmott, 1999); el género (Alvesson \& Billing, 2009; Ashcraft, 2009; Calás \& Smircich, 1992, 2006); la identidad (Thomas, 2009); el liderazgo (Alvesson \& Spicer, 2012; Alvesson \& Sveningsson, 2003; Petit, 2009); el poscolonialismo (Prasad, 2003a); la racionalidad (Townley, 2008); la comunicación (Deetz, 1995; Sotirin \& Tyrell, 1998); la globalización (Banerjee, Carter \& Clegg, 2009; Bannerjee, Chio \& Mir, 2009; Clegg, Ibarra \& BuenoRodriques, 1999); el cambio (Henriksen, Nørreklit, Jørgensen, Christensen \& O'Donnell, 2004; Morgan \& Spicer, 2009; Perret, 2009; Pichault, 2011); la ética (Carter, Clegg, Kornberger, Laske \& Messner, 2007; Klikauer, 2010; Muhr, Sørensen \& Vallentin, 2010) y la responsabilidad social (Banerjee, 2007; Rabassó \& Rabassó, 2009), el conocimiento (Alvesson, 2004; Pesqueux, 2009) y la cultura (Alvesson, 2002; Chan, 2000). 


\section{LOS ESTUDIOS CRIITICOS EN ADMINISTRACIÓN: ORIGEN, EVOLUCIÓN Y POSIBILIDADES DE APORTE AL DESARROLLO DEL CAMPO DE LOS ESTUDIOS ORGANIZACIONALES EN AMÉRICA LATINA}

En lo relacionado con temas disciplinares más especializados, vinculados directamente con el campo de los estudios organizacionales, también se destacan otros múltiples desarrollos. Una síntesis de los principales temas y de algunos trabajos representativos de cada uno de ellos se presenta en la Tabla 2.

A pesar de la multiplicidad de fuentes, temas, métodos y perspectivas, los CMS pueden distinguirse a partir de tres criterios básicos: i) una posición no performativa; ii) una actitud hacia la desnaturalización; y iii) el trabajo a partir de la reflexividad y de una aproximación característica hacia la investigación (Alvesson et al., 2009a; Fournier \& Grey, 2000; Shenhav, 2003).

En primer lugar, se encuentra la apuesta por tener una posición no performativa (Fournier \& Grey,
2000), tanto frente a las relaciones entre los individuos en el contexto organizacional como frente al ejercicio de la investigación. En efecto, se piensa que esas relaciones no deben ser evaluadas desde un punto de vista únicamente instrumental -i.e. "(...) en la optimización de la relación global entre entrada [input] y salida [output]" (Lyotard, 1984, 11) -. En otras palabras, se considera que ellas no deben ser estimadas como relaciones en las que se busca: i) maximizar el desempeño y los resultados derivados de la interacción; ii) minimizar, disimular o eliminar las anomalías frente al funcionamiento habitual de las cosas; y particularmente, iii) privilegiar (o considerar únicamente) la eficiencia y la producción frente al conocimiento o la verdad.

Esto no quiere decir necesariamente que no exista la intención en los CMS de tratar de modificar las prác-

Tabla 2. Temas y principales trabajos de los CMS vinculados con el campo de los estudios organizacionales ${ }^{4}$

\begin{tabular}{|c|c|}
\hline Tema & Trabajos destacados \\
\hline $\begin{array}{l}\text { La metodología de la investiga- } \\
\text { ción en el campo }\end{array}$ & $\begin{array}{l}\text { Alvesson \& Deetz (2000); Alvesson \& Sköldberg (2009); Duberley \& Johnson (2009); Jeanes \& Huzzard (2014); } \\
\text { Kelemen \& Rumens (2008); Prasad (2005); Winter (2011). }\end{array}$ \\
\hline Los recursos humanos & Ben Hassel \& Raveleau (2011); Cazal (2008, 2011); Dany (2009); Elliott \& Turnbull (2008); Léonard (2011). \\
\hline La estrategia & $\begin{array}{l}\text { Alvesson \& Willmott (1995); Clegg, Carter, Kornberger \& Schweitzer (2011); Knights \& Morgan (1991); Phillips } \\
\text { \& Dar (2009). }\end{array}$ \\
\hline El mercadeo & Marion (2009); Skålén, Fellesson \& Fougère (2008); Tadajewski \& Brownlie (2008); Tadajewski \& Maclaran (2009). \\
\hline La teoría de la desorganización & Hassard, Kelemen \& Cox (2008). \\
\hline La teoría de la organización & Böhm (2006); Jones \& Munro (2005); Linstead (2004); Mills, Simmons \& Mills (2005). \\
\hline La contra administración & Clegg, Kornberger, Carter \& Rhodes (2006); Parker (2001, 2002a, 2009); André Spicer \& Böhm (2007). \\
\hline La administración & Clegg, Kornberger \& Pitsis (2011); Harding (2003). \\
\hline El comportamiento organizacional & Wilson (2010). \\
\hline La administración internacional & Jack \& Westwood (2009). \\
\hline La gestión de proyectos & Hodgson \& Cicmil (2006). \\
\hline Los sistemas de información & Brooke (2009). \\
\hline El análisis organizacional & Casey (2002). \\
\hline El emprendimiento & Janssen \& Schmitt (2011). \\
\hline La contabilidad & Berland \& Pezet (2009). \\
\hline Las finanzas & Rainelli-Le Montagner (2009). \\
\hline La auditoría & Ramirez (2009). \\
\hline La filosofía en el campo & Jones \& Bos (2006). \\
\hline
\end{tabular}

4 Fuente: Elaboración propia. 
ticas administrativas existentes en el contexto organizacional, así como los supuestos, discursos, teorías $y$ tradiciones que las soportan. Su proyecto consiste en adelantar una crítica con sentido e impacto, una crítica no solo contemplativa sino también comprometida y activa (Akella, 2008; King \& Learmonth, 2014; Phillips, 2006; Wickert \& Schaefer, 2014). Por esta razón, al interior de los CMS se impulsa el desarrollo de una "performatividad crítica" (e.g. Roscoe $\&$ Chillas, 2013), es decir, un tipo de performatividad con inclinación hacia la acción (Taskin, 2011; Veltz, 2011) y con un interés de intervención (a partir de la reflexión y la comprensión) (Sanabria, 2006), una que modifique los elementos cuestionables de la realidad organizacional haciendo uso de tácticas como la afirmación de la ambigüedad, el trabajo con misterios, la acción comunicativa aplicada, la exploración de "heterotopías", la micro-emancipación, el pragmatismo progresivo y la búsqueda de potencialidades presentes (Alvesson \& Spicer, 2012; Spicer, Alvesson \& Kärreman, 2009) $)^{5}$.

En segundo lugar, se encuentra el cuestionamiento a los fenómenos de "naturalización" (Alvesson \& Willmott, 1996; Fournier \& Grey, 2000) (i.e. del tipo: "ese es el orden natural de las cosas") o normalización de hechos no naturales, irracionales o fuera de orden, presentes en el contexto organizacional. Hechos que en nombre de fenómenos como la globalización, la competencia, la necesidad de rentabilidad y productividad, el libre comercio o, incluso, el desempleo y la pobreza (por el riesgo del individuo de caer en estas situaciones y la necesidad de conformarse, por ejemplo, con tener trabajo sin importar de qué tipo o en qué condiciones), son sugeridos aparentemente como "inevitables", como si no existiera alguna otra alternativa posible frente a ellos.

Estos hechos hacen referencia entonces a la existencia -que ha devenido más o menos natural en el contexto organizativo, en nombre de ese tipo de discursos- de situaciones perjudiciales como el es- trés, los problemas de salud, la subordinación, la explotación, la inequidad, el acoso, el abuso, el tedio, la jerarquía, el deterioro de la privacidad, la desesperación, la presión excesiva, la necesidad de conformismo, las limitaciones a la libre comunicación, la humillación, el engaño y la mentira, el cinismo, la discriminación, el detrimento de la moralidad, el machismo, el privilegio del trabajo frente a cualquier otra dimensión humana (e.g., la familia) y otras -e.g. , la parte 3 de la compilación de Barling \& Cooper (2008), así como el trabajo de Hearn (2003) -.

En el contexto de los CMS estas son situaciones que hablan de la existencia de un "lado oscuro de los negocios" (Alvesson, 2008, 14; Alvesson et al., 2009a, 8; Helin, Jensen, Sandström \& Clegg, 2011; Victor \& Stephens, 1994). Un lado que es necesario poner en evidencia (Alvesson, 2003; Cederstrom \& Fleming, 2012; Courpasson \& Thoenig, 2008; Taskin, 2011) con el fin de pensar, revelar y/o proponer alternativas (Fleming \& Spicer, 2007), sin importar incluso si estas pueden eventualmente ser consideradas como utópicas (Parker, 2002b; Parker, Fournier \& Reedy, 2007).

Desde esta perspectiva es necesario deconstruir el discurso de la administración, conservar una postura crítica, una "criticalidad" (Grey \& Willmott, 2005a) que permita cuestionar los imperativos que se establecen en el contexto de las organizaciones con el fin de legitimar y conservar el statu quo (Alvesson \& Ashcraft, 2009), así como revelar posibles alternativas (teóricas y prácticas) a esos elementos que han sido demeritados, ignorados u ocultados por la corriente dominante en el campo de los estudios organizacionales (Fournier \& Grey, 2000).

En tercer lugar, se encuentra la búsqueda de una actitud reflexiva (Alvesson et al., 2009a; Fournier \& Grey, 2000) y de una aproximación característica hacia la investigación. La actitud reflexiva procura poner en cuestión los supuestos básicos de la tradi-

5 En la división de CMS (Critical Management Studies Division) de la Academy of Management, se afirma algo similar: Conducidos por un deseo compartido de cambiar esta situación (i.e. el hecho de que las organizaciones se convierten frecuentemente en instrumentos de dominación y explotación), encaminamos nuestra investigación, enseñanza y práctica al desarrollo de interpretaciones críticas de la administración y la sociedad y a generar alternativas radicales 
ción investigativa en el campo de los estudios organizacionales, en particular la visión objetivista, positivista y cientificista que ha caracterizado a la vertiente norteamericana de los mismos (Sanabria, Saavedra \& Smida, 2014a).

Se trata de cuestionar entonces la manera en la que la investigación se ha desarrollado tradicionalmente en el campo y cómo esa tradición ha influido en el conocimiento que se produce. Para esto es necesario considerar incluso lo que implica para el propio investigador el hecho de encontrarse él mismo al interior del discurso de los CMS y, por lo tanto, verse afectado por sus supuestos.

Se trata, finalmente, de considerar de manera explícita las relaciones de poder y las estructuras de control en las que el investigador y su trabajo están inmersos (Shenhav, 2003) y de hacer explícitos los supuestos epistemológicos, ontológicos y metodológicos que guían su actividad investigativa (Fournier \& Grey, 2000).

La aproximación característica hacia la investigación de los CMS procura, entre otras cosas, en función de conceptos como el de "voice" _ "la habilidad de un individuo, un grupo o una nación de articular y expresar sus experiencias, sus demandas y sus quejas [... que] representa la lucha por el reconocimiento" (Gabriel, 2008, 317)-, dar voz a quienes no la tienen en el contexto de la práctica y/o la teoría (Alvesson, Hardy \& Harley, 2008; Rhodes, 2002; Spicer et al., 2009) y rescatar con ello el rol de actores que aparentemente no son protagónicos (Alvesson \& Ashcraft, 2009; Grant \& Iedema, 2005; Stoecker, Tryon \& Hilgendorf, 2009). De hecho, los CMS, a través de su actividad de investigación, tienden a ponerse de parte de los más débiles en el marco de las relaciones organizacionales (Alvesson, 2008).

Conceptos complementarios como el de listening (Alvesson \& Deetz, 2000, 68), por otro lado, remiten a la necesidad de "escuchar": i) las voces de los participantes y los elementos que están en el trasfondo de lo que ellas dicen (i.e. discursos dominantes, su- puestos, valores, etc.); ii) los temas que se esconden en esas voces y que implican elementos que son importantes para los individuos pero que también son de interés a nivel político, moral, ético o teórico; y iii) las múltiples $-e$ incluso competitivas- voces que intervienen mientras se buscan explicaciones teóricas. En otras palabras, este concepto invita a realizar un ejercicio de escucha desde la pluralidad.

En los CMS se trabaja principalmente desde una perspectiva cualitativa (Steinberg \& Cannella, 2012; Taskin, 2011), inclinada hacia el "trabajo de campo reflexivo y las entrevistas" (Alvesson \& Ashcraft, 2009, 62). La crítica se soporta esencialmente -no de manera exclusiva- en la tradición europea de los estudios organizacionales a la que se ha hecho mención, así como en el interés de comprensión y elicitación que subyace en los estudios desarrollados en ese contexto. De hecho, la investigación en este campo comparte múltiples elementos clave con la "investigación interpretativa, cualitativa" tradicional, aunque le añade un componente crítico (Alvesson \& Deetz, 2000, 69). De acuerdo con Alvesson (2008, 18), el "trabajo de campo u otras clases de investigación empírica al interior de los CMS puede ser hecho con toda clase de técnicas, pero alguna clase de metodología de desnaturalización caracteriza el conjunto de la aproximación interpretativa".

Finalmente, en la investigación que se realiza en el marco de los CMS se considera la naturaleza plural de los fenómenos estudiados (Alvesson \& Deetz, 2000). Un tercer concepto importante aparece entonces, el de "multidimensionalidad", que indica la necesidad de asumir una mirada crítica y, en particular, de considerar que "son necesarios diferentes modos de análisis para tratar con las complejidades y los niveles del comportamiento humano en las organizaciones" (Thompson \& McHugh, 2002, 16).

Para facilitar la comprensión de lo que ellos implican, a continuación, en la Tabla 3, se incorpora una síntesis de los conceptos básicos a los que se acaba de hacer referencia. Estos conceptos, aunque por supuesto no son los únicos que podrían llegar a ser

6 Utilizado inicialmente por Hirschman (1970) para designar una forma de respuesta del actor frente al deterioro de sus condiciones en firmas, organizaciones y Estados. 
considerados (cf. Tadajewski, Maclaran, Parsons \& Parker, 2011b), ocupan un lugar protagónico en los fundamentos de la actividad investigativa que ha dado forma a los CMS y, por ello, son dignos de ser destacados.

Aunque por todos estos elementos los CMS han sido vistos como una alternativa epistemológica a la que Shenhav $(2003,203)$ llamó la NATO (North American Theory of Organizations), desde 2008 ellos se han vinculado directamente con la institución académica más representativa de la corriente dominante, la Academy of Management. En efecto, los CMS se han incorporado en el seno de esa institución y hoy constituyen una de sus 23 divisiones. Como antecedentes de este hecho es importante resaltar dos acontecimientos, a saber: i) en The British Academy of Management se había dado ya una apertura similar a los CMS dos años antes (Fournier \& Grey, 2000, 28); y ii) de acuerdo con Taskin \& Willmott (2008), debe ser considerado también como un antecedente importante la Labour Process Conference, realizada en 1983 en el Reino Unido, que reunió a diversos participantes con una actitud crítica frente a la administración, muchos de ellos provenientes de escuelas de formación en este campo.

La constitución de la división de Critical Management Studies en el seno de la Academy of Management es un proceso que inició con el primer taller realizado sobre este tema en la pre-conferencia de los Academy of Management Meetings de 1998, en San Diego, Estados Unidos; que continuó después con otros encuentros en calidad de "grupo de in-

Tabla 3. Seis conceptos básicos para la investigación que da forma a los CMS7

\begin{tabular}{|c|c|}
\hline Concepto & Definición \\
\hline Performatividad crítica & $\begin{array}{l}\text { Un tipo de performatividad con inclinación hacia la acción (Taskin, 2011; Veltz, 2011) y la intervención soportadas en la reflexión y } \\
\text { la comprensión (Sanabria, 2006). Una performatividad que, en particular, trata de modificar los elementos que son cuestionables en } \\
\text { la realidad organizacional. }\end{array}$ \\
\hline $\begin{array}{c}\text { Crítica a la naturali- } \\
\text { zación }\end{array}$ & $\begin{array}{l}\text { Un cuestionamiento al hecho de considerar algunos fenómenos como parte del orden natural de las cosas a pesar de que ellos sean } \\
\text { inconvenientes o incluso puedan llegar a ser malvados. Se pone en cuestión la normalización de esos hechos que son irracionales, } \\
\text { perversos, incorrectos o que están por fuera de orden, pero que, sin embargo, están presentes en el contexto organizacional y llegan } \\
\text { a ser considerados como una parte de él a la que simplemente hay que acostumbrarse porque su presencia es casi natural (Alvesson } \\
\text { \& Willmott, 1996; Fournier \& Grey, 2000). }\end{array}$ \\
\hline Reflexividad & $\begin{array}{l}\text { Un permanente cuestionamiento a la manera en la que la investigación se ha desarrollado tradicionalmente en el campo de la admi- } \\
\text { nistración y a la forma en la que esa tradición ha influido en el conocimiento producido. Implica considerar, muy particularmente, las } \\
\text { relaciones de poder y las estructuras de control en las que el investigador y su trabajo están inmersos (Shenhav, 2003) y de hacer } \\
\text { explícitos los supuestos que guían su actividad investigativa (Fournier \& Grey, 2000). }\end{array}$ \\
\hline Voice & $\begin{array}{l}\text { Un rescate de "la habilidad [que tienen] un individuo, un grupo o una nación de articular y expresar sus experiencias, sus demandas } \\
\text { y sus quejas [... y su] lucha por el reconocimiento" (Gabriel, 2008, 317). Se trata de dar voz a quienes no la tienen en el contexto } \\
\text { de la práctica y/o la teoría (Alvesson, Hardy \& Harley, 2008; Rhodes, 2002; Spicer et al., 2009) y de rescatar así el rol de actores } \\
\text { que aparentemente no son protagónicos en el contexto organizacional (Alvesson \& Ashcraft, 2009; Grant \& ledema, 2005; Stoecker, } \\
\text { Tryon \& Hilgendorf, 2009). }\end{array}$ \\
\hline Listening & $\begin{array}{l}\text { Una necesidad de escuchar las voces de los participantes y los elementos que están en el trasfondo de lo que ellas dicen (i.e. dis- } \\
\text { cursos dominantes, supuestos, valores, etc.). Se trata de oír los temas que se esconden en esas voces y que implican elementos que } \\
\text { son importantes para los individuos pero que también son de interés a nivel político, moral, ético o teórico. Se considera necesario } \\
\text { atender a las múltiples voces que intervienen mientras se buscan explicaciones teóricas. }\end{array}$ \\
\hline Multidimensionalidad & $\begin{array}{l}\text { Una constante necesidad de asumir una mirada crítica y, en particular, de considerar que "son necesarios diferentes modos de } \\
\text { análisis para tratar con las complejidades y los niveles del comportamiento humano en las organizaciones" (Thompson \& McHugh, } \\
2002,16 \text { ). }\end{array}$ \\
\hline
\end{tabular}

7 Fuente: Elaboración propia. 
terés" y que se consolidó en 2008 cuando la AOM le otorgó al grupo el estatus de "división". Es una división muy activa que cuenta, a finales de 2014, con 717 miembros (531 académicos, 12 eméritos, 58 ejecutivos y 116 estudiantes) ${ }^{8}$.

La premisa básica de esta división está, sin embargo, claramente vinculada al espíritu que anima a los CMS de base originalmente europea: "que las características estructurales de la sociedad contemporánea, como el imperativo de ganancias, el patriarcado, la inequidad racial y la irresponsabilidad ecológica, convierten frecuentemente a las organizaciones en instrumentos de dominación y explotación"'.

La vinculación de los CMS con la institución más insigne de la corriente dominante es vista de dos formas. Por un lado, como el resultado de la apertura de la Academy of Management hacia nuevos discursos y perspectivas, una muestra de que ella está dispuesta a acoger las miradas críticas y un reconocimiento a la existencia de la pluralidad al interior del campo de la administración (Eden, 2003). En resumen, es considerada como una gran oportunidad (Walsh \& Weber, 2002).

Pero por otro lado, es vista también como una prueba del hecho de que quien originalmente está por fuera de la corriente dominante, una vez logra tener voz y empieza a ser escuchado y reconocido, es absorbido por la fuerza del más poderoso (i.e. los CMS constituyen tan solo una más de las 23 divisiones de la Academy of Management). Esta vinculación es vista entonces como un acto realizado por el más débil (o que se encontraba al margen), quien termina cediendo frente a la fuerza y las posibilidades que representa estar con el más poderoso. Esto constituye propiamente un ejercicio de "colonización" (Fournier \& Grey, 2000, 24) que se da a través de la fuerza del diálogo, en el encuentro entre el poderoso y el débil. El diálogo es entonces, en este contexto, en palabras de Burrell (1996, 650), el "arma del poderoso".

Este hecho puede ser visto, en efecto, en términos de los propios CMS, como la "producción de un consentimiento" en el que la integración favorece al grupo dominante y en el que la actividad de ambos, en adelante, responde a un consentimiento más bien "manufacturado" (Alvesson \& Deetz, 2006, 262).

En cualquier caso, la evolución de los CMS ha sido destacada. Pruebas de ello son su institucionalización al interior de la Academy of Management y la acogida que estos han tenido: i) en revistas reconocidas e identificadas como representativas de la corriente dominante como Academy of Management Journal (Eden, 2003), Academy of Management Review (Alvesson \& Willmott, 1992a), Academy of Management Annals (Adler, Forbes \& Willmott, 2007) y Academy of Management Learning \& Education (Learmonth, 2007; Reynolds \& Vince, 2004); y ii) en otras publicaciones que mantienen tradicionalmente una relación más cercana (De Woot \& Kleymann, 2011; Taskin \& Willmott, 2008) o, en algunos casos, una vinculación explícita y directa (Parker \& Thomas, 2011), con el discurso que les ha dado forma.

Entre este segundo grupo de revistas se destacan ${ }^{10}$ : Organization: The Critical Journal of Organization; Theory and Society; Tamara Journal for Critical Organization Inquiry; EJROT: Electronic Journal of Radical Organization Theory; Ephemera: Theory \& Politics in Organization; Organization Studies; Human Relations; Scandinavian Journal of Management; Critical Perspectives on International Business; Culture \& Organization; Management; Management Learning; Journal of Organizational Change Management; Gender, Work \& Organization; Organization \& Environment; Critical Perspectives on Accounting; Alternative Perspectives on Finance and Accounting; Journal of Workplace Rights; $M$ \& OH: Management \& Organizational History; Studies in Language and Capitalism; Equality, Diversity and Inclusion: An International Journal; Journal of Cultural Economy; y Sociology.

Los CMS constituyen un campo actual y dinámico. Una prueba adicional de su vigencia, desarrollo y búsqueda de consolidación es la publicación de tra-

\footnotetext{
Tomado de: http://group.aomonline.org/cms/Index.htm

9 Tomado de: http://group.aomonline.org/cms/about us/default.html

10 Tomado de: http://criticalmanagement.org/Journals
} 
bajos relevantes que dan forma, aunque con múltiples matices, a su tradición. Entre estos trabajos se destacan:

- Los textos de Alvesson \& Willmott (1992b), Alvesson \& Deetz (2000), Warwick's Organizational Behaviour Staff (2001), Faulkner (2002), Alvesson \& Willmott (2003), Grey \& Willmott (2005b), Cox, LeTrent J., Voronov \& Weir (2009); Alvesson, Bridgman \& Willmott (2009b); Alvesson (2011); y Alvesson \& Willmott (2011).

- Las series Advances in Organization Studies, cuyo primer volumen fue publicado en 1999 (editada por Stewart Clegg y Ralph E. Stablein) ${ }^{11}$ y Dialogues in Critical Management Studies (editada por Richard Hull).

- Dos compilaciones a saber: i) la editada por Golsorkhi, Huault \& Leca (2009), titulada Les études critiques en management: une perspective francaise ; y ii) la editada por Taskin \& De Nanteuil (2011), titulada Perspectives critiques en management: pour une gestion citoyenne; así como la instauración de la serie KC Études Critiques en Management, editada por AllardPoesi \& Loilier (2009) en la revista Économies \& Sociétés. Estas iniciativas conservan un interés de divulgación entre la comunidad francófona, similar al que ha animado, en el mundo hispanohablante, la compilación hecha por Fernández (2007) titulada Vigilar y Organizar: Una introducción a los "Critical Management Studies"; el trabajo de Saavedra (2009); y la realización misma de este artículo.

Son también evidencias de la vitalidad y vigencia de los CMS:

- Los números especiales que han sido publicados respecto a ellos en la Academy of Management Review y el Administrative Science Quar- terly (Alvesson et al., 2009a) y en otras revistas (e.g., British Journal of Management, 2010, Vol. 21, Supplement s1; Journal of Business Ethics, 2010, Vol. 94, No. 2 Supplement; Management, 2011, Vol. 14, No. 5), entre los que se destaca, por su interés para los fines de este artículo, es el de Critical Perspectives on International Business (2005, Vol. 6., No. 2/3), cuyo título es: Critical international management and international critical management: Perspectives from Latin America ${ }^{12}$

- La existencia de cursos (Clegg, Dany \& Grey, 2011; Hagen, Miller \& Johnson, 2003) y de otros esfuerzos por introducir a los CMS en la enseñanza (Beaujolin-Bellet \& Grima, 2011; Clegg, et al., 2011; Cunliffe, Forray \& Knights, 2002; De Woot \& Kleymann, 2011; Grey, 2004).

- Los programas académicos de maestría (Lancaster University) y doctorado (Fournier \& Grey, $2000,28)$ existentes en este campo, así como las escuelas de formación en negocios que en Inglaterra, por ejemplo las pertenecientes a la Univesidad de Leicester y la Queen Mary en la Universidad de Londres (Taskin \& Willmott, 2008) - y, en otros países, están vinculadas hoy directamente con los CMS.

Finalmente, se destacan como pruebas de su desarrollo y consolidación la existencia, al interior de la división en el Academy of Management, de incentivos como el CMS Best Dissertation of the Year, el Best Paper, el Dark Side Writting Case Competition, el Best Student Paper y el Best Developmental Reviewer; así como la realización regular de la International Critical Management Studies Conference (que tuvo lugar por primera vez en 1999) y la inclusión de los CMS en otras reuniones como la del European Group for Organizational Studies (EGOS), la Standing Conference for Organizational Symbolism (SCOS) y en un amplio número de otras conferencias y eventos ${ }^{13}$ que han incorporado ya el tema y

11 Aunque esta serie está dedicada al campo más amplio de los estudios organizacionales, muchas de sus obras se relacionan directa o indirectamente con el campo de los CMS. Ver: http://benjamins.com/\#catalog/books/aios y http://www.cbspress.dk/Series-Advances-in.831.0.html

12 Ver Ibarra et al. (2010).

13 Ver : http://www.criticalmanagement.org/event 
que se realizan en países como Francia, Japón, Australia, Nueva Zelanda, Brasil, México, Inglaterra y Estados Unidos (Alvesson et al., 2009a).

Los CMS, generados inicialmente con base en el Reino Unido (Fernández, 2007), desarrollados y fortalecidos en Europa y sustentados en las tendencias antipositivistas, no funcionales y posmodernistas de sociólogos "vinculados a las business schools durante los años 1980 y 1990” (Shenhav, 2003, 203), constituyen hoy un campo mucho más expandido (incluso en Estados Unidos) y dinámico, que plantea una serie de elementos alternativos que, por su naturaleza, pueden ser muy útiles para el desarrollo de los estudios organizacionales en América Latina, aunque desde la observación de algunas restricciones, tendencias y observaciones que es necesario considerar.

\section{Tendencias, limitaciones y consideraciones para el trabajo futuro en Latinoamérica}

Como se ha puesto en evidencia, los CMS son un discurso que procura ser alternativo a la corriente principal representada, en general, por la vertiente norteamericana de los estudios organizacionales (Augier et al., 2005; Sanabria, Saavedra \& Smida, 2014a). Es un campo en el que, por la naturaleza crítica que lo caracteriza y las tensiones que han emergido a lo largo de su desarrollo, se ha dado forma a algunas tendencias que es posible identificar en la actualidad y que podrían ser importantes para su evolución en el futuro. Tres tendencias, en particular, son relevantes para los fines de este trabajo.

En primer lugar, gracias al uso de la reflexividad (Alvesson \& Willmott, 2011), un concepto básico para los CMS (Tabla 3), existe una creciente tendencia a cuestionar no solo la corriente principal del campo de la administración sino también la perspectiva que ha promovido la propia corriente crítica (Alvesson, 2008). Son objeto de reflexión profunda, en este sentido, su popularización (Fournier \& Grey, 2000) e institucionalización (Eden, 2003; Walsh \& Weber, 2002), así como sus objetivos, fundamentos, supuestos, métodos, posibilidades de aplicación e impacto efectivos y la coherencia entre su discurso y sus acciones (Cox, LeTrent, Voronov \& Weir, 2009; Delbridge, 2014; King \& Learmonth, 2014; Koss Hartmann, 2014; McLean \& Alcadipani, 2008; Mills \& Mills, 2013; Smith, 2008; Spicer, Alvesson \& Kärreman, 2009).

En segundo lugar, existe un interés creciente por cuestionar no solo las prácticas administrativas y las teorías que han procurado explicarlas y desarrollarlas (Akella, 2008), sino también, cada vez más, las prácticas que los académicos -en las escuelas de negocios que dan soporte a la reproducción tanto de la corriente principal como de la crítica- establecen para apoyar y promover, cada uno, sus propias perspectivas (Clegg, Dany \& Grey, 2011; Cunliffe, Forray \& Knights, 2002; Rowlinson \& Hassard, 2011). Esta tendencia se acompaña de un interés por determinar la posibilidad de desarrollo e impacto real que tienen los CMS en el contexto educativo y, a través de él, en la realidad de las organizaciones (Breen, 2012; Contu, 2009; Grey, 2004; Hibbert, 2013; Learmonth, 2007; Reynolds \& Vince, 2004; Voronov, 2008).

En tercer lugar, existe un interesante y promisorio cuestionamiento a la inexistencia de una perspectiva crítica deslocalizada, que esté abierta verdadera y ampliamente a la diversidad demográfica y cultural de la sociedad global. Se plantea la necesidad de desarrollar, hacia el futuro, una perspectiva crítica en el campo de la administración que, en pro de la unificación, la institucionalización, la coherencia y la madurez (Phillips, 2006), no ignore las especificidades de las diferentes regiones existentes en el planeta (Ibarra, 2008a; Letiche, 2006; Tatli, 2012).

En el marco de estas tendencias y del desarrollo global de los ECM, es posible identificar algunos elementos, entre los que se destacan dos en particular, que limitan su desarrollo en diversos lugares del mundo (Durango, 2005; Medina, 2007, 2010; Vergara, 2001) y, en particular, en el contexto latinoamericano.

Por un lado, está el hecho de que los CMS han adoptado la tradición hegemónica e institucionalizada del campo que consiste en publicar sus resultados de investigación en inglés (Tietze \& Dick, 2013) y en circunscribir sus aportes -aunque de manera mucho 
más plural que la corriente principal y no sin tratar de hacer algunos esfuerzos para cambiar esta situación (Willmott, 2011)- esencialmente a los países del norte. Por otro lado, se encuentra el hecho de que la crítica promovida dentro de los CMS tiene unos fundamentos históricos, culturales, políticos, económicos, teóricos y empíricos, distintos a los podrían dar soporte a una perspectiva crítica con origen en la idiosincrasia e identidad latinoamericanas.

Con respecto a la primera de las limitaciones señaladas es significativo que la mayor parte de las publicaciones realizadas en el campo hayan sido desarrolladas y/o divulgadas en inglés (Alvesson, 2011; Alvesson et al., 2009b; Alvesson \& Willmott, 2011, 2012, 1992b, 2003), un idioma que es considerado en el contexto de la ciencia -y en otros (Crystal, 2003)como una lengua franca (Held, 1999, 346). El supuesto detrás de esa práctica es que esto se trata de algo "natural" (Tabla 3), algo que simplemente debe ser aceptado pues, de hecho, el inglés es una lengua que cualquier académico en el mundo requiere conocer adecuadamente (Steyaert \& Janssens, 2013). Sin embargo, este supuesto no se realiza en un número importante de los académicos que conforman el campo de los estudios organizacionales en Latinoamérica ni en otras regiones del mundo. El inglés, de hecho, como el chino mandarín estándar, es hablado tan solo por un poco más de mil millones de personas (Dalby, 2012, 291), en un mundo poblado actualmente por más de siete veces esa cantidad de seres humanos.

Este hecho refuerza la idea de que, tal y como se ha desarrollado el campo, a través de sus prácticas y mecanismos de reproducción, él continúa dando forma a una élite, que, aunque más diversa que antes gracias a los CMS, sigue siendo, finalmente, un grupo restringido de personas con acceso privilegiado a conocimientos 'de punta'. Los CMS dan muestras así, en su propia evolución, de la realización de la tesis foucaultiana respecto a la firme relación entre conocimiento y poder. Estos participan, de ese modo, de manera deliberada o no, en la reproducción de una inequidad que impide la emancipación de múltiples actores por fuera de círculos en los que se mueven tanto la corriente principal como la corriente crítica. Este es un tipo de relación a la cual, por su natu- raleza y vocación, los CMS deberían enfrentarse de manera mucho más explícita y decidida.

Este hecho, que puede ser considerado como una limitante en materia de comunicación de las ideas, pero no necesariamente de la producción de las mismas, restringe la posibilidad de integración de la comunidad que forma los estudios organizacionales en los países que se encuentran por fuera de los centros usuales de producción académica del campo. Esto sucede porque los miembros de esa comunidad mantienen todos la mirada fija en el mismo lugar, es decir, en los dos grandes ejes que alimentan tanto la corriente principal como la de los discursos alternativos del tipo CMS, en los autores, trabajos, problemáticas y teorías que allí se producen. Esos miembros no realizan, por esta razón, una reflexión crítica autónoma y autentica, inspirada en su propio contexto y en sus propios problemas e idiosincrasia, un ejercicio a partir del cual pueda ser posible lograr su propio desarrollo y construir un reconocimiento internacional.

Con respecto a la segunda limitación se encuentra que la mirada europea de los estudios organizacionales y, en vinculación con ella, la de los CMS, se fundamenta en una historia y unas condiciones sociales, culturales, económicas, tecnológicas y geopolíticas evidentemente distintas a las latinoamericanas. Esto conduce a la necesidad de que la comunidad propia del campo en esta región se esfuerce por guardar distancia y evite asumir de manera acrítica tanto el discurso hegemónico como el discurso alternativo que representan los CMS.

Ahora bien, la tradición latinoamericana no se alimenta en este momento, mayoritariamente, de una mirada crítica frente a los Estados Unidos (menos aún frente a Europa) y, si lo hiciera, no lo realizaría por hechos como los que en su momento inspiraron el desarrollo de la corriente europea de los estudios organizacionales (i.e. la Guerra de Vietnam, los movimientos contraculturales surgidos alrededor de Mayo del 68, la reacción contra el imperialismo norteamericano y europeo, etc.). Latinoamérica, en general, no tiene una tradición anglófona, como sí la posee una destacada parte del continente europeo (el eje de desarrollo fundamental de los CMS es el 
Reino Unido). Además, la tradición en esta región está marcada por un pasado colonial español y portugués, un pasado que ha marcado su historia, que ha dejado huellas en su forma de pensamiento y que, entre otras cosas, ha dificultado la construcción de una verdadera identidad común.

Este último aspecto, en particular, es singularmente importante. En el contexto de los CMS, una teoría que cobra cada vez más fuerza, la teoría poscolonial, constituye una alternativa interesante para la tradición latinoamericana del campo de los estudios organizacionales. Ella es una vía de investigación que conviene valorizar y desarrollar para el futuro de este campo en la región, en la que hay mucho por construir y aportar con miras al contexto global. A este respecto es significativo que en la edición de las probablemente más importantes compilaciones sobre esa teoría, editadas por Prasad (2003b, 2012) y en el número especial de la revista Critical Perspectives on International Business (2008, Vol. 4, No. 2/3) dedicado a ella y editado por Banerjee y Prasad, los académicos latinoamericanos se encuentren esencialmente ausentes. Tal carencia puede, sin embargo, considerarse una oportunidad de incursionar en este campo. Ella puede ser aprovechada si se avanza, por ejemplo, sobre la base de los trabajos que tanto sobre la perspectiva crítica (con sentido regional) como sobre la teoría postcolonial (desde una consideración esencialmente epistemológica) desarrolló el lamentablemente fallecido (el 19 de mayo de 2013, a sus 56 años, en la cúspide de su carrera) profesor Eduardo Ibarra Colado, de la Universidad Autónoma Metropolitana de México (Clegg et al., 1999; Ibarra, 1985, 2006a, 2006b, 2006c, 2008a, 2008b; Ibarra, Faria \& Guedes, 2010; Ibarra \& Montaño, 1985).

Reconocer la figura de autores como él (una de las actividades básicas en el desarrollo de cualquier campo de conocimientos), tratar de difundir más ampliamente sus trabajos (lo que es necesario en la dinámica de la actividad científica) y procurar construir sobre los avances realizados por el conjunto de investigadores que han aportado también al campo de los estudios organizacionales desde el contexto latinoamericano (e.g., Aktouf, Carvajal Baeza \& Cruz Kronfly, 2003; Sanabria, Saavedra \& Smida, 2014a; Echeverry, Chanlat \& Dávila, 1996; Ibarra, 2008b), podría contribuir a la revalorización de la idiosincrasia de esta región, de sus problemáticas, autenticidad e identidad (cf. Sanabria, Saavedra \& Smida, 2014b). Esto podría ayudar a la construcción de una perspectiva autóctona capaz de proyectar sus aportes al mundo.

En la Tabla 4, se retoman de manera sintética los principales elementos que dan forma al análisis aquí planteado.

De lo que se trata entonces, hacia el futuro, es de liberarse de las múltiples ataduras que implica el colonialismo (epistemológico, metodológico, ideológico, etc.) y de identificar y desafiar las maneras en que los discursos dominantes han afectado la subjetividad y han contribuido a dar forma a la identidad de los académicos, investigadores y practicantes en el campo. Se trata de deshacerse de la imagen que nos identifica como seres de alguna forma 'inferiores', 'dependientes' o 'sirvientes' (Latin American Subaltern Studies Group, 1995), de independizar -lo que no es sinónimo de 'desarticular'- el pensamiento latinoamericano y de valorizar sus propias filosofías (Nuccetelli, Schutte \& Bueno, 2010), tradición y fundamentos. Se trata de poner en la agenda del campo de los estudios organizacionales y de los CMS (Delbridge, 2014; Huault, Perret \& Spicer, 2014; Koss Hartmann, 2014) asuntos propios de esta región, de emanciparse tanto de una ortodoxia como de una crítica canónicas, así como de las ideologías, instituciones, intereses, e identidades (las cuatro I) que las representan a ambas y de abordar, desde una performatividad crítica, las problemáticas propias de este contexto con el fin de dar una nueva forma a las organizaciones que operan en esta parte del planeta.

Esto es posible, por ejemplo, si se aprende de las lecciones que deja el desarrollo de los CMS y de la vertiente europea de los estudios organizacionales (Sanabria, Saavedra \& Smida, 2014a), con la que estos guardan una íntima relación. En particular, si se considera la valorización que se hizo en ese contexto, en su momento, de los planteamientos de autores como Franco Ferraresi, David Hickson, Jean-Claude Thoenig y Renate Mayntz en vinculación con una institución representativa del mismo 
Tabla 4. Principales tendencias, limitaciones y consideraciones para el trabajo futuro de los CMS en Latinoamérica ${ }^{14}$

\begin{tabular}{|c|c|c|}
\hline Tendencias & Limitaciones & Consideraciones \\
\hline $\begin{array}{l}\text { El cuestionamiento no solo de la corriente principal } \\
\text { en el campo de la administración sino también de } \\
\text { la perspectiva que ha promovido la propia corriente } \\
\text { crítica. Se revalúa la popularización y la instituciona- } \\
\text { lización de los CMS, así como sus objetivos, funda- } \\
\text { mentos, supuestos, métodos, posibilidades de apli- } \\
\text { cación e impacto y la coherencia entre su discurso } \\
\text { y sus acciones. }\end{array}$ & $\begin{array}{l}\text { Los CMS han adoptado la tradición hegemónica e } \\
\text { institucionalizada del campo que consiste en pu- } \\
\text { blicar sus resultados de investigación en inglés. } \\
\text { Hay una aceptación implícita de la naturalización } \\
\text { de esta práctica y del reforzamiento de un cono- } \\
\text { cimiento desarrollado por una élite y destinado } \\
\text { a una élite. }\end{array}$ & $\begin{array}{l}\text { La teoría poscolonial, constituye una alternativa } \\
\text { interesante para la tradición latinoamericana del } \\
\text { campo de los estudios organizacionales. Ella es } \\
\text { una vía de investigación que conviene valorizar y } \\
\text { desarrollar para el futuro de este campo en la re- } \\
\text { gión. Este es un espacio en el que hay mucho por } \\
\text { construir y aportar con miras al contexto global. }\end{array}$ \\
\hline $\begin{array}{l}\text { El cuestionamiento no solo de las prácticas adminis- } \\
\text { trativas y las teorías, que han procurado explicarlas } \\
\text { y desarrollarlas, sino también de aquellas que los } \\
\text { académicos en las escuelas de negocios han estable- } \\
\text { cido para apoyar y promover, cada uno, sus propias } \\
\text { perspectivas. Hay un interés creciente por determinar } \\
\text { la posibilidad de desarrollo e impacto real que tienen } \\
\text { los CMS en el contexto educativo y, a través de él, en } \\
\text { la realidad de las organizaciones. }\end{array}$ & $\begin{array}{l}\text { Los CMS han circunscrito sus aportes, aunque de } \\
\text { manera mucho más plural que la corriente princi- } \\
\text { pal y no sin hacer algunos esfuerzos para cambiar } \\
\text { esta situación (Willmott, 2011), esencialmente a } \\
\text { los países del norte. }\end{array}$ & $\begin{array}{l}\text { Conviene reconocer los trabajos que tanto sobre } \\
\text { la perspectiva crítica (con sentido regional) como } \\
\text { sobre la teoría postcolonial (desde una conside- } \\
\text { ración epistemológica) desarrolló el profesor } \\
\text { Eduardo Ibarra Colado, de la Universidad Autó- } \\
\text { noma Metropolitana de México. Reconocer este } \\
\text { esfuerzo y el de otros múltiples y destacados au- } \\
\text { tores en la región es una tarea fundamental para } \\
\text { el desarrollo de una identidad regional. }\end{array}$ \\
\hline $\begin{array}{l}\text { El cuestionamiento a la inexistencia de una perspec- } \\
\text { tiva crítica deslocalizada, abierta verdadera y amplia- } \\
\text { mente a la diversidad demográfica y cultural de la so- } \\
\text { ciedad global. Se plantea la necesidad de desarrollar, } \\
\text { hacia el futuro, una perspectiva crítica en el campo de } \\
\text { la administración que, a pesar del interés existente } \\
\text { por la unificación, la institucionalización, la coheren- } \\
\text { cia y la madurez, no ignore las especificidades de las } \\
\text { diferentes regiones presentes en el planeta. }\end{array}$ & $\begin{array}{l}\text { La crítica promovida dentro de los CMS tiene } \\
\text { unos fundamentos históricos, culturales, políti- } \\
\text { cos, económicos, teóricos y empíricos, distintos } \\
\text { a los podrían dar soporte a una perspectiva crítica } \\
\text { con origen en la idiosincrasia e identidad latinoa- } \\
\text { mericanas. }\end{array}$ & $\begin{array}{l}\text { Es necesario superar el colonialismo (episte- } \\
\text { mológico, metodológico, ideológico, etc.) e } \\
\text { identificar y desafiar los discursos dominantes y } \\
\text { su influjo en la identidad de los académicos, in- } \\
\text { vestigadores y practicantes en el campo. Hay que } \\
\text { independizar el pensamiento latinoamericano; } \\
\text { valorizar sus propias filosofías, tradición y fun- } \\
\text { damentos; aprender del desarrollo de los CMS y } \\
\text { de la vertiente europea de los estudios organiza- } \\
\text { cionales y fortalecer instituciones como CLADEA. }\end{array}$ \\
\hline
\end{tabular}

como el European Group for Organizational Studies (EGOS). América Latina podría, de manera similar, apalancar su propio desarrollo en los avances realizados, entre muchos otros, por profesores como Eduardo Ibarra Colado y en instituciones plurales y altamente representativas de la región como el Consejo Latinoamericano de Escuelas de Administración (CLADEA). Pero para que CLADEA asuma en este contexto el papel renovador que otrora asumió EGOS en Europa debe estar imbuida por un nuevo espíritu, debe tener un interés emancipatorio y propositivo aún más explícito y debe tener una mayor vocación reflexiva y crítica (Ibarra, 2008b). Solo de esta manera podrá construir sus propios aportes con independencia tanto de la corriente ortodoxa, principalmente norteamericana, como de la corriente crítica, esencialmente europea.

\section{Conclusión}

En este artículo se han presentado, esencialmente: i) los orígenes, supuestos y planteamientos básicos de los CMS; ii) su evolución y estado actual; y iii) las tendencias, limitaciones y consideraciones para el trabajo futuro de los estudios organizacionales en América Latina.

14 Fuente: Elaboración propia. 


\section{LOS ESTUDIOS CRIITICOS EN ADMINISTRACIÓN: ORIGEN, EVOLUCIÓN Y POSIBILIDADES DE APORTE AL DESARROLLO DEL CAMPO DE LOS ESTUDIOS ORGANIZACIONALES EN AMÉRICA LATINA}

A partir de la revisión hecha al discurso de los CMS en el marco del campo de los estudios organizacionales se ha puesto en evidencia que las dos principales limitaciones que en la actualidad tiene ese discurso para apalancar el desarrollo de este campo en nuestro contexto consisten principalmente en: i) su inscripción en la hegemónica, institucionalizada y restrictiva tradición anglófona del campo y el hecho de que sus aportes, así como los de la corriente principal en el mismo, se concentran en los países del norte; y ii) el reconocimiento de que la crítica promovida al interior de los CMS tiene unos fundamentos históricos, culturales, políticos, económico, teóricos y prácticos distintos a los que podrían motivar una crítica sustentada en la identidad latinoamericana.

Frente a la identificación de estas dos importantes restricciones se han planteado algunos elementos que permitirían promover el desarrollo autóctono de una comunidad latinoamericana de los estudios organizacionales que, descolonizada tanto de la corriente hegemónica principal, como de la ya institucionalizada perspectiva crítica europea, pueda independizar (y no por ello aislar o desarticular) su propio pensamiento, formación, investigación y prácticas. Para ello, es necesario identificar los avances logrados hasta este momento por parte de diversos autores, mirando no hacia afuera, como es habitual, sino hacia adentro de la región y apalancarse en una renovada institucionalidad como la que pueden llegar a representar asociaciones tales como el Consejo Latinoamericano de Escuelas de Administración (CLADEA).

\section{Referencias}

Ackroyd, S. \& Thompson, P. (1999). Organizational misbehaviour. Londres - Thousand Oaks: SAGE.

Adler, P. (1999). Building better bureaucracies. En: Academy of Management Executive, 13(4): 36-47

Adler, P., Forbes, L. \& Willmott, H. (2007). Critical Management Studies. En: The Academy of Management Annals, 1(1): 119-179.

Akella, D. (2008). A reflection on critical management studies. En: Journal of Management and Organization, 14(1): 100-110.

Aktouf, O., Carvajal Baeza, R., \& Cruz Kronfly, F. (eds.) (2003). El lado inhumano de las organizaciones. Cali: Universidad del Valle, Facultad de Ciencias de la Administración.

Allard-Poesi, F. \& Loilier, T. (2009). Qu'est-ce que la critique en Sciences du Management? Que pourrait-elle être ? En: Économies et Sociétés, KC(1): 1975-1999.
Alvesson, M. (1987). Organization theory and technocratic consciousness: rationality, ideology, and quality of work. Berlin - Nueva York: W. De Gruyter.

Alvesson, M. (2002). Understanding organizational culture. Londres - Thousand Oaks: SAGE.

Alvesson, M. (2003). Critical organization theory. En: Czarniawska, B. \& Sevón, G. (eds.) The northern lights: organization theory in Scandinavia (pp. 151-174). Malmö - Oslo - Copenhague: Liber - Abstrakt - Copenhagen Business School Press.

Alvesson, M. (2004). Knowledge work and knowledge-intensive firms. Oxford - Nueva York: Oxford University Press.

Alvesson, M. (2008). The future of critical management studies. En: Barry, D. \& Hansen, H. (eds.) The SAGE handbook of new approaches in management and organization (pp. 13-30). Los Angeles: SAGE.

Alvesson, M. (ed.) (2011). Classics in critical management studies. Cheltenham: Edward Elgar.

Alvesson, M. \& Ashcraft, K. (2009). Critical methodology in management and organization research. En : Buchanan, D. \& Bryman, A. (eds.) The SAGE handbook of organizational research methods (pp. 61-77). Los Angeles - Londres: SAGE.

Alvesson, M. \& Billing, Y. (2009). Understanding gender and organizations (2nd ed.). Thousand Oaks: SAGE.

Alvesson, M. \& Deetz, S. (2000). Doing critical management research. Thousand Oaks - Londres: SAGE.

Alvesson, M. \& Deetz, S. (2006). Critical theory and postmodernism approaches to organizational studies. En: Clegg, S., Hardy, C., Lawrence, T. \& Nord, W. (eds.) The SAGE handbook of organization studies (pp. 255-283). 2nd ed. Londres: SAGE.

Alvesson, M. \& Sköldberg, K. (2009). Reflexive methodology: new vistas for qualitative research (2nd ed.). Londres: SAGE.

Alvesson, M. \& Spicer, A. (2012). Critical leadership studies: the case for critical performativity. En: Human Relations, 65(3): 367-390.

Alvesson, M. \& Sveningsson, S. (2003). Good visions, bad micromanagement and ugly ambiguity: contradictions of (non-)leadership in a knowledge-intensive organization. En: Organization Studies, 24(6): 961-988.

Alvesson, M. \& Willmott, H. (1992a). On the idea of emancipation in management and organization studies. En: Academy of Management Review, 17(3): 432-464.

Alvesson, M. \& Willmott, H. (1995). Strategic management as domination and emancipation: from planning and process to communication and praxis. En: Shrivastava, P. \& Stubbart, C. (eds.) Advances in strategic management, 12A: Challenges from outside the Mainstream: 85-112. Greenwich, Conn. Londres: JAI Press.

Alvesson, M. \& Willmott, H. (1996). Making sense of management: a critical introduction. Londres - Thousand Oaks: SAGE.

Alvesson, M. \& Willmott, H. (2011). Critical Management Studies [Four-Volume Set]. Londres: SAGE.

Alvesson, M. \& Willmott, H. (2012). Making sense of management: a critical introduction (2nd ed.). Thousand Oaks: SAGE.

Alvesson, M. \& Willmott, H. (eds.) (1992b). Critical management studies. Londres - Newbury Park: SAGE.

Alvesson, M. \& Willmott, H. (eds.) (2003). Studying management critically. Londres - Thousand Oaks: SAGE.

Alvesson, M., Bridgman, T. \& Willmott, H. (2009a). Introduction. En: Alvesson, M., Bridgman, T. \& Willmott, H. (eds.), The Oxford handbook of Critical Management Studies (pp. 1-26). NuevaYork: Oxford University Press. 
Alvesson, M., Bridgman, T. \& Willmott, H. (eds.) (2009b). The Oxford handbook of Critical Management Studies. Nueva York: Oxford University Press.

Alvesson, M., Hardy, C. \& Harley, B. (2008). Reflecting on reflexivity: reflexive textual practices in organization and management theory. En: Journal of Management Studies, 45(3): 480-501.

Anthony, P. (1977). The ideology of work. Londres: Tavistock Publications.

Ashcraft, K. (2009). Gender and divesity: other ways to "make a difference". En: Alvesson, M., Bridgman, T. \& Willmott, H. (eds.) The Oxford handbook of Critical Management Studies (pp. 304-327). Nueva York: Oxford University Press.

Assoun, P. (2012). LÉcole de Francfort. Paris: Presses universitaires de France.

Audet, M. \& Déry, R. (2000). La science réfléchie. Quelques empreintes de l'épistémologie des sciences de l'administration. En: Côté, M. \& Hafsi, T. (eds.) Le management aujourd'hui. Une perspective nord-américaine (pp. 35-49). Laval - Paris: Presses de l'Université Laval, Economica.

Augier, M. \& March, J. (2011). The roots, rituals, and rhetorics of change: North American business schools after the Second World War. Stanford, California: Stanford Business Books.

Augier, M., March, J. \& Ni Sullivan, B. (2005). Notes on the evolution of a research community: organization studies in anglophone North America, 1945-2000. En: Organization Science, 16(1): 85-95.

Banerjee, S. (2003). Who sustain whose development? Sustainable development and the reinvention of nature. En: Organization Studies, 24(1): 143-180.

Banerjee, S. (2007). Corporate social responsibility: the good, the bad and the ugly. Cheltenham: Edward Elgar.

Banerjee, S. \& Prasad, A. (2008). Introduction to the Special Issue on "Critical reflections on management and organizations: a postcolonial perspective". En: Critical Perspectives on International Business, 4(2/3): 90-98.

Banerjee, S., Carter, C. \& Clegg, S. (2009). Management globalization. En: Alvesson, M., Bridgman, T. \& Willmott, H. (eds.) The Oxford handbook of critical management studies (pp. 186-212). Nueva York: Oxford University Press.

Bannerjee, S., Chio, V. \& Mir, R. (eds.) (2009). Organizations, markets and imperial formations: towards an anthropology of globalization. Cheltenham: Edward Elgar.

Barling, J. \& Cooper, C. (eds.) (2008). The SAGE handbook of organizational behavior (Vol. 1: Micro Approaches). Los Angeles - Londres: SAGE.

Beaujolin-Bellet, R. \& Grima, F. (2011). Ces enseignants-chercheurs qui introduisent la critique dans les écoles de commerce françaises. En: Taskin, L. \& De Nanteuil, M. (eds.) Perspectives critiques en management : pour une gestion citoyenne (pp. 197-208). Bruselas: De Boeck.

Ben Hassel, F. \& Raveleau, B. (2011). Les dimensions critiques de l'enseignement de la GRH : plaidoyer pour un management renouvelé. En: Taskin, L. \& De Nanteuil, M. (eds.) Perspectives critiques en management : pour une gestion citoyenne (pp. 209-224). Bruselas: De Boeck.

Bendix, R. (1956/2001). Work and authority in industry: managerial ideologies in the course of industrialization. New Brunswick: Transaction.

Berland, N. \& Pezet, A. (2009). Quand la comptabilité colonise l'économie et la société. En: Golsorkhi, D., Huault, I. \& Leca,
B. (eds.) Les études critiques en management : une perspective francaise (pp. 133-162). Quebec: Presses de l'Université Laval.

Böhm, S. (2006). Repositioning organization theory: ompossibilities and srategies. Houndmills, Basingstoke, Hampshire England ; Nueva York: Palgrave Macmillan.

Boje, D., Gephart, R. \& Thatchenkery, T. (eds.) (1996). Postmodern management and organization teory. Thousand Oaks: SAGE.

Boltanski, L. (2009). De la critique: précis de sociologie de l'émancipation. Paris: Gallimard.

Bort, S. \& Schiller-Merkens, S. (2011). Reducing uncertainty in scholarly publishing: concepts in the field of organization studies, 1960-2008. En: Schmalenbach Business Review, 63(4): 337-360.

Braverman, H. (1998). Labor and monopoly capital: the degradation of work in the Twentieth Century (25th anniversary ed.). Nueva York: Monthly Review Press.

Breen, J. (2012). Exploring criticality in management education: to be critical or not to be critical is the question. Tesis de doctorado, University of Sheffield, Sheffield.

Bronner, S. \& Kellner, D. (eds.) (1989). Critical theory and society: a reader. Nueva York: Routledge.

Brooke, C. (2009). Critical management perspectives on information systems. Oxford: Butterworth-Heinemann.

Burrell, G. (1988). Modernism, post modernism and oganizational analysis 2: the contribution of Michel Foucault. En: Organization Studies, 9(2): 221-235.

Burrell, G. (1994). Modernism, postmodernism and organizational analysis 4: the Contribution of Jürgen Habermas. En: Organization Studies, 15(1): 1-45.

Burrell, G. (1996). Normal science, paradigms, metaphors, discourses and genealogies of analysis. En: Clegg, S., Hardy, C. \& Nord, W. (eds.) Handbook of Organization Studies (pp. 642-658) Londres - Thousand Oaks: SAGE.

Burrell, G. (1999). Normal science, paradigms, metaphors, discourses and genealogies of analysis. En : Clegg, S. \& Hardy, C. (eds.) Studying organization: theory \& method (pp. 388-404). Londres Thousand Oaks: SAGE.

Burrell, G. (2009). Handbooks, swarms, and living dangerously. En: Alvesson, M., Bridgman, T. \& Willmott, H. (eds.) The Oxford handbook of Critical Management Studies (pp. 551-562). Oxford - Nueva York: Oxford University Press.

Calás, M. \& Smircich, L. (1991). Voicing seduction to silence leadership. En: Organization Studies, 12(4): 567-601.

Calás, M. \& Smircich, L. (1992). Re-writing gender into organizational theorizing: directions from feminist perspectives. En: Reed, M. \& Hughes, M. (eds.) Rethinking organization: new directions in organization theory and analysis (pp. 227-253). Londres: SAGE.

Calás, M. \& Smircich, L. (2006). From the 'woman's point of view' ten yars later: Towards a feminist organization studies. En : Clegg, S., Hardy, C., Lawrence, T. \& Nord, W. (eds.) The Sage Handbook of Organization Studies. (2nd ed. Vol. 284-346). Londres: SAGE.

Camic, C. \& Xie, Y. (1994). The statistical turn in American social science: Columbia University, 1890 to 1915. En: American Sociological Review, 59(5): 773-805.

Campbell, J. (2009). Poststructuralism in critical management studies. En: Alvesson, M., Bridgman, T. \& Willmott, H. (eds.) The Oxford handbook of Critical Management Studies (pp. 76-98). Nueva York: Oxford University Press. 


\section{LOS ESTUDIOS CRIITICOS EN ADMINISTRACIÓN: ORIGEN, EVOLUCIÓN Y POSIBILIDADES DE APORTE AL DESARROLLO DEL CAMPO DE LOS ESTUDIOS ORGANIZACIONALES EN AMÉRICA LATINA}

Carter, C., Clegg, S., Kornberger, M., Laske, S. \& Messner, M. (eds.) (2007). Business ethics as practice: representation, reflexivity and performance. Cheltenham: Edward Elgar.

Casey, C. (2002). Critical analysis of organizations: theory, practice, revitalization. Londres - Thousand Oaks: SAGE.

Cazal, D. (2008). Recherches critiques en GRH : intérêts, connaissance et action. En: Revue de Gestion des Ressources Humaines, (70): 69-87.

Cazal, D. (2011). Porter un regard critique sur la gestion internationale des ressources humaines, un défi impossible? En: Taskin, L. \& De Nanteuil, M. (eds.) Perspectives critiques en management: pour une gestion citoyenne (pp. 185-194). Bruselas: De Boeck.

Cederstrom, C. \& Fleming, P. (2012). Dead man working. Hants: Zero Books.

Chan, A. (2000). Critically constituting organization. Amsderdam - Philadelphia, PA: John Benjamins Pub. Co.

Child, J. (2011). British management thought: a critical analysis. Londres: Routledge.

Clegg, S. (1989). Frameworks of power. Londres - Newbury Park: SAGE.

Clegg, S. (1990). Modern organizations: organization studies in the postmodern world. Londres - Thousand Oaks - New Delhi: SAGE.

Clegg, S., Kornberger, M., Carter, C. \& Rhodes, C. (2006). For management? En: Management Learning, 37(1): 7-27.

Clegg, S. \& Bailey, J. (2008). Introduction. En: Clegg, S. \& Bailey, J. (eds.) International encyclopedia of organization studies (pp. $\mathrm{x}$ |iii-x|viii). Los Angeles - Londres: SAGE.

Clegg, S. \& Dunkerley, D. (1977a). Introduction: critical issues in organizations. En: Clegg, S. \& Dunkerley, D. (eds.) Critical issues in organizations (pp. 1-6). Londres: Routledge and Kegan Paul.

Clegg, S. \& Dunkerley, D. (1980). Organization, class and control. Londres: Routledge and Kegan Paul.

Clegg, S. \& Dunkerley, D. (eds.) (1977b). Critical issues in organizations. Londres: Routledge and Kegan Paul.

Clegg, S. \& Haugaard, M. (eds.) (2012). Power and organizations [Four-Volume Set]. Los Angeles: SAGE.

Clegg, S., Carter, C., Kornberger, M. \& Schweitzer, J. (2011). Strategy: theory \& practice. Los Angeles: SAGE.

Clegg, S., Dany, F. \& Grey, C. (2011). Introduction to the special issue critical management studies and managerial education: new contexts? New agenda? En: Management, 14(5): 272-279.

Clegg, S., Ibarra, E. \& Bueno-Rodriques, L. (eds.). (1999). Global management: universal theories and local realities. Londres Thousand Oaks: SAGE.

Clegg, S., Kornberger, M. \& Pitsis, T. (2011). Managing \& organizations: an introduction to theory \& practice (3rd ed.). Los Angeles - Londres: SAGE.

Collinson, D. (2003). Identities and insecurities: selves at work. En: Organization, 10(3): 527-547.

Collinson, D. \& Hearn, J. (1996). Breaking the silence: on men, masculinities and managements. En: Collinson, D. \& Hearn, J. (eds.) Men as managers, managers as men: Critical perspectives on men, masculinities and managements (pp. 1-24). Londres: SAGE.

Contu, A. (2009). Critical management education. En: Alvesson, M., Bridgman, T. \& Willmott, H. (eds.) The Oxford handbook of Critical Management Studies (pp. 536-550). Nueva York: Oxford University Press.

Cooper, R. \& Burrell, G. (1988). Modernism, postmodernism and organizational analysis: an introduction. En: Organization Studies, 9(1), 91-112.
Courpasson, D. \& Thoenig, J. (2008). Quand les cadres se rebellent. París: Vuibert.

Cox, J., LeTrent, T., Voronov, M. \& Weir, D. (eds.) (2009). Critical management studies at work: negotiating tensions between theory and practice. Cheltenham - Northampton: Edward Elgar.

Crystal, D. (2003). English as a global language (2nd ed). Cambridge - Nueva York: Cambridge University Press.

Cunliffe, A. (2008). Will You still need me ... When I'm 64? The future of CMS. En: Organization, 15(6): 936-938.

Cunliffe, A., Forray, J. \& Knights, D. (2002). Considering management education: insights from critical management studies. En : Journal of Management Education, 26(5): 489-495.

Cusset, F. (2005). French theory: Foucault, Derrida, Deleuze \& Cie et les mutations de la vie intellectuelle aux États-Unis. París: La Découverte.

Czarniawska, B. (1999). Writing management: organization theory as a literary genre. Oxford: Oxford University Press.

Czarniawska, B. \& Sevón, G. (1996). Translating organizational change. Berlín: Walter de Gruyter.

Dalby, D. (2012). The linguasphere register of the World's languages and speech communities. Section: "The Linguasphere in 10 pages". Vol. 1. Hebron, Wales, UK.: Observatoire linguistique / Linguasphere Observatory / Bhasha Vishwa. Disponible en: http://www.linguasphere.info/lcontao/tl_files/pdf/part1/P11-TitlePagesAndContent.pdf

Dany, F. (2009). Recherche critique en GRH et critique de la recherche: un voyage au coeur de la littérature qui met à mal certaines idées reçues. En: Golsorkhi, D., Huault, I. \& Leca, B. (eds.), Les études critiques en management : une perspective francaise (pp. 307-328). Quebec: Presses de l'Université Laval.

De Rond, M. \& Miller, A. (2005). Publish or perish: Bane or boon of academic life? En: Journal of Management Inquiry, 14(4): 321-329.

De Woot, P. \& Kleymann, B. (2011). Changer le paradigme culturel dans l'enseignement du management: un impératif, pas une option. En: Taskin, L. \& De Nanteuil, M. (eds.) Perspectives critiques en management : pour une gestion citoyenne (pp. 225-238). Bruselas: De Boeck.

Deetz, S. (1992). Democracy in an age of corporate colonization: developments in communication and the politics of everyday life. Albany: State University of New York Press.

Deetz, S. (1995). Transforming communication, transforming business: building responsive and responsible workplaces. Cresskill, N.J.: Hampton Press.

Delbridge, R. (2014). Promising futures: CMS, post-disciplinarity, and the new public social science. En: Journal of Management Studies, 51(1): 95-117.

Duberley, J. \& Johnson, P. (2009). Critical management methodology. En: Alvesson, M., Bridgman, T. \& Willmott, H. (eds.) The Oxford handbook of Critical Management Studies (pp. 345-368). Nueva York: Oxford University Press.

Durand, J. (2012). LÉcole de Francfort. Paris: Gallimard.

Durango, C. (2005). Fundamentación epistemológica de los estudios organizacionales. Medellín: Universidad Pontificia Bolivariana.

Durepos, G., Mills, A. \& Weatherbee, T. (2012). Theorizing the past: realism, relativism, relationalism and the reassembly of Weber. En: Management \& Organizational History, 7(3): 267-281.

Echeverry, R., Chanlat, A. \& Dávila, C. (eds.) (1996). En busca de una administración para América Latina: experiencias y desafíos. Santiago de Cali: Univesidad del Valle. 
Eden, D. (2003). From the editors: critical management studies and the Academy of Management Journal: challenge and counterchallenge. En: The Academy of Management Journal, 46(4): 390-394.

Edwards, R. (1979). Contested terrain: the transformation of the workplace in the Twentieth Century. Nueva York: Basic Books.

Elliott, C. \& Turnbull, S. (eds.) (2008). Critical thinking in human resource development. Londres: Routledge.

Faulkner, D. (ed.) (2002). Strategy: critical perspectives on business and management (Four-Volume Set]. Londres: Routledge.

Fernández, C. (ed.) (2007). Vigilar y organizar: una introducción a los "Critical management studies". Madrid: Siglo XXI de España.

Fleming, P. \& Spicer, A. (2007). Contesting the corporation: struggle, power and resistance in organizations. Cambridge - Nueva York: Cambridge University Press.

Forester, J. (2003). On fieldwork in a Habermasian way: critical ethnography and the extra-ordinary character of ordinary professional work. En: Alvesson, M. \& Willmott, H. (eds.) Studying management critically (pp. 46-65). Londres - Thousand Oaks: SAGE.

Fournier, V. \& Grey, C. (2000). At the critical moment: conditions and prospects for Critical Management Studies. En : Human Relations, 53(1): 7-32.

Gabriel, Y. (1999). Organizations in depth: the psychoanalysis of organizations. Londres: SAGE.

Gabriel, Y. (2008). Organizing words: a critical thesaurus for social and organization studies. Oxford - Nueva York: Oxford University Press.

Golsorkhi, D., Huault, I. \& Leca, B. (eds.) (2009). Les études critiques en management: une perspective francaise. Quebec: Presses de l'Université Laval.

Gordon, R. \& Howell, J. (1959). Higher education for business. Nueva York: Columbia University Press.

Granjon, M. (2009). La critique selon Michel Foucault. En: Golsorkhi, D., Huault, I. \& Leca, B. (eds.) Les études critiques en management: une perspective francaise (pp. 67-79). Quebec: Presses de l'Université Laval.

Grant, D. \& Iedema, R. (2005). Discourse analysis and the study of organizations. En: Text, 25(1): 37-66.

Grey, C. (1996). Towards a critique of managerialism: The contribution of Simone Weil. En: Journal of Management Studies, 33(5): 591-611.

Grey, C. (2004). Reinventing business schools: the contribution of critical management education. En: Academy of Management Learning \& Education, 3(2): 178-186.

Grey, C. \& Willmott, H. (2005a). Introduction. En: Grey, C. \& Willmott, H. (eds.) Critical management studies: a reader (pp. 1-15). Oxford: Oxford University Press.

Grey, C. \& Willmott, H. (eds.) (2005b). Critical management studies: a reader. Oxford: Oxford University Press.

Hagen, R., Miller, S. \& Johnson, M. (2003). The 'disruptive consequences' of introducing a critical management perspective onto an MBA programme the lecturers' view. En: Management Learning, 34(2): 241-257.

Hancock, P. \& Tyler, M. (2001). Work, postmodernism and organization: a critical introduction. Londres - Thousand Oaks: SAGE.

Harding, N. (2003). The social construction of management: texts and identities. Londres - Nueva York: Routledge.

Hardy, C. (ed.) (1995). Power and politics in organizations. Aldershot: Dartmouth.
Hassard, J., Kelemen, M. \& Cox, J. (2008). Disorganization theory: explorations in alternative organizational analysis. Londres: Routledge.

Hatchuel, A., Pezet, E., Starkey, K. \& Lenay, O. (2005). Gouvernement, organisation et entreprise : l'héritage de Michel Foucault. Quebec: Presses de l'Université Laval.

Hearn, J. (2003). Organization violations in practice: a case study in a university setting. En: Culture and Organization, 9(4): 253-273.

Held, D. (1999). Global transformations: politics, economics and culture. Cambridge: Polity Press.

Helin, S., Jensen, T., Sandström, J. \& Clegg, S. (2011). On the dark side of codes: domination not enlightenment. En: Scandinavian Journal of Management, 27(1): 24-33.

Henriksen, L., Nørreklit, L., Jørgensen, K., Christensen, J. \& O'Donnell, D. (2004). Dimensions of change: conceptualising reality in organisational research. Copenhagen, Denmark: Copenhagen Business School Press.

Herrero, S. (2012). ECO: estudios críticos sobre organización. Comunicación, organización y sociedad en la paradoja de nuestro tiempo. Buenos Aires: Temas Grupo Editorial.

Hibbert, P. (2013). Approaching reflexivity through reflection: issues for Critical Management Education. En: Journal of Management Education, 37(6): 803-827

Hodgson, D. \& Cicmil, S. (eds.) (2006). Making projects critical. Basingstoke: Palgrave Macmillan.

Horkheimer, M. (2002). Crítica de la razón instrumental. Madrid: Trotta.

Huault, I., Perret, V. \& Spicer, A. (2014). Beyond macro- and micro- emancipation: Rethinking emancipation in organization studies. En: Organization, 21(1): 22-49.

Ibarra, E. (1985). Notas para el estudio de las organizaciones en América Latina a partir de la reflexión crítica de la teoría de la organización. En: Ibarra, E. \& Montaño, L. (eds.) Ensayos críticos para el estudio de las organizaciones en México. Cuadernos universitarios, 29: 13-62. México: Universidad Autónoma Metropolitana - Iztapalapa.

Ibarra, E. (1991). Notas para el estudio de las organizaciones en América Latina a partir de la reflexión crítica de la teoría de la organización. En: Ibarra, E. \& Montaño, L. (eds.) Ensayos críticos para el estudio de las organizaciones en México (pp. 27-66). México: Universidad Autónoma Metropolitana, Unidad Iztapalapa - Miguel Angel Porrúa.

Ibarra, E. (2006a). ¿Estudios organizacionales en América Latina?: transitando del centro hacia las orillas. En: De La Garza Toledo, E. (ed.) Teorías sociales y estudios del trabajo: nuevos enfoques (pp. 88-107). Rubí, Barcelona / México: Anthropos / UAM, Unidad Iztapalapa.

Ibarra, E. (2006b). Mexico's management and organization studies challenges in the twenty-first century: practices, knowledge, and reencounters. En: Management Research, 4(3) : 181-192.

Ibarra, E. (2006c). Organization studies and epistemic coloniality in Latin America: thinking otherness from the margins. En: Organization, 13(4) : 463-488.

Ibarra, E. (2008a). Is there any future for critical management studies in Latin America? Moving from epistemic coloniality to 'trans-discipline'. En: Organization, 15(6) : 932-935.

Ibarra, E. (2008b). Organizational literature, Latin American. En : Clegg, S. \& Bailey, J. (eds.) International encyclopedia of organization studies (pp. 1128-1133). Los Angeles - Londres: SAGE. 


\section{LOS ESTUDIOS CRIITICOS EN ADMINISTRACIÓN: ORIGEN, EVOLUCIÓN Y POSIBILIDADES DE APORTE AL DESARROLLO DEL CAMPO DE LOS ESTUDIOS ORGANIZACIONALES EN AMÉRICA LATINA}

Ibarra, E. \& Montaño, L. (eds.) (1985). Ensayos críticos para el estudio de las organizaciones en México. En: Cuadernos universitarios, 29. México: Universidad Autónoma Metropolitana - Iztapalapa.

Ibarra, E. \& Montaño, L. (eds.) (1991). Ensayos críticos para el estudio de las organizaciones en México. México: Universidad Autónoma Metropolitana, Unidad Iztapalapa - Miguel Angel Porrúa.

Ibarra, E., Faria, A. \& Guedes, A. (2010). Introduction to the special issue on "Critical international management and international critical management: perspectives from Latin America". En: Critical Perspectives on International Business, 6(2/3): 86-96.

Ingram, D. (ed.) (2010). The history of continental philosophy. En: Critical theory to structuralism: philosophy, politics and the human sciences, 5. Durham: Acumen.

Jack, G. \& Westwood, R. (2009). International and cross-cultural management studies: a postcolonial reading. Basingstoke: Palgrave Macmillan.

Jackall, R. (1988). Moral mazes: the world of corporate managers. Nueva York - Oxford: Oxford University Press.

Janssen, F. \& Schmitt, C. (2011). L'entrepreneur, héros des temps modernes? Pour une analyse critique de l'entrepreneuriat. En: Taskin, L. \& De Nanteuil, M. (eds.), Perspectives critiques en management: pour une gestion citoyenne (pp. 163-184). Bruselas: De Boeck.

Jeanes, E. \& Huzzard, T. (eds.) (2014). Critical management research: Reflections from the field. Londres - Thousand Oaks - New Delhi - Singapore: SAGE.

Jennings, P., Schulz, M., Patient, D., Gravel, C. \& Ke, Y. (2005). Weber and legal rule evolution: The closing of the iron cage? En: Organization Studies, 26(4): 621-653.

Jones, C. \& Bos, R. (2006). Philosophy and organisation. Londres: Routledge.

Jones, C. \& Munro, R. (eds.) (2005). Contemporary organization theory. Malden - Oxford: Blackwell

Kalinowski, I. (2009). La critique selon Max Weber. Les sciences sociales peuvent-elles et doivent-elles prétendre à «l'objectivité»? En: Golsorkhi, D. Huault, I. \& Leca, B. (eds.) Les études critiques en management: une perspective francaise (pp. 81-96). Quebec: Presses de l'Université Laval.

Karlsson, J. (2012). Organizational misbehaviour in the workplace: narratives of dignity and resistance. England - Nueva York: Palgrave Macmillan

Kelemen, M. \& Rumens, N. (2008). An introduction to critical management research. Los Angeles - Londres: SAGE.

Khurana, R. (2007). From higher aims to hired hands: The social transformation of american business schools and the unfulfilled promise of management as a profession. Princeton: Princeton University Press.

King, D. \& Learmonth, M. (2014). Can critical management studies ever be 'practical'? A case study in engaged scholarship. Human Relations, Online First.

Klikauer, T. (2010). Critical management ethics. Houndmills, Basingstoke: Palgrave Macmillan.

Knights, D. (1992). Changing spaces: the disruptive impact of a new epistemological location for the study of management. En: Academy of Management Review, 17(3): 514-536.

Knights, D. \& Morgan, G. (1991). Corporate strategy, organizations, and subjectivity: a critique. En: Organization Studies, 12(2): 251-273.
Knights, D. \& Willmott, H. (1989). Power and subjectivity at work: from degradation to subjugation in social relations. En: Sociology, 23(4): 535-558.

Knights, D. \& Willmott, H. (1999). Management lives: power and identity in work organizations. Londres - Thousand Oaks: SAGE.

Koss Hartmann, R. (2014). Subversive functionalism: for a less canonical critique in critical management studies. En: Human Relations, 67(5): 611-632.

Kunda, G. (1992). Engineering culture: control and commitment in a high-tech corporation. Filadelfia: Temple University Press.

Latin American Subaltern Studies Group (1995). Founding statement. En: Beverley, J., Aronna, M. \& Oviedo, J. (eds.), The postmodernism debate in Latin America (pp. 135-146). Durham: Duke University Press.

Learmonth, M. (2007). Critical management education in action: personal tales of management unlearning. En: Academy of Management Learning \& Education, 6(1): 109-113.

Léonard, E. (2011). Gestion des ressources humaines, institutions et régulations sociales: pour ouvrir la perspective. En: Taskin, $\mathrm{L}$. \& De Nanteuil, M. (eds.) Perspectives critiques en management: pour une gestion citoyenne (pp. 135-147). Bruselas: De Boeck.

Letiche, H. (2006). Critical management studies (not) in The Netherlands. En: Critical Perspectives on International Business, 2(3): 170-182.

Linstead, S. (2004). Organization theory and postmodern thought. Londres: SAGE.

Locke, R. (1996). The collapse of the American management mystique. Oxford - Nueva York: Oxford University Press.

Lounsbury, M. \& Carberry, E. (2005). From King to Court Jester? Weber's fall from grace in organizational theory. En: Organization Studies, 26(4): 501-525.

Lyotard, J. (1984). The postmodern condition: a report on knowledge. Minneapolis: University of Minnesota Press.

March, J. (2007). The study of organizations and organizing since 1945. En: Organization Studies, 28(1): 9-19.

Marglin, S. (1974). What do bosses do? En: Review of Radical Political Economics, 6(2): 60-112.

Marion, G. (2009). Le marketing et le concert de la critique. En: Golsorkhi, D., Huault, I. \& Leca, B. (eds.). Les études critiques en management: une perspective francaise (pp. 99-132). Quebec: Presses de l'Université Laval.

Marsden, R. \& Townley, B. (1999). The owl of Minerva: reflections on theory in practice. En: Clegg, S. \& Hardy, C. (eds.) Studying organization: theory \& method (pp. 405-421). Londres - Thousand Oaks: SAGE.

Martin, J. (1990). Deconstructing organizational taboos: the suppression of gender conflict in organizations. En: Organization Science, 1(4): 339-359.

Mattelart, A. \& Neveu, É. (2008). Introduction aux cultural studies (Nouvelle ed.). París: La Découverte.

McKinlay, A. \& Starkey, K. (eds.) (1998). Foucault, management and organization theory: from panopticon to technologies of self. Londres - Thousand Oaks - New Delhi: SAGE.

McLean, C. \& Alcadipani, R. (2008). Critical management studies: some reflections. En: BAR - Brazilian Administration Review, 5(1): 70-84.

McQuillan, M. (Ed.). (2001). Deconstruction:a reader. Nueva York: Routledge.

McQuillan, M. \& Willis, I. (eds.) (2010). The origins of deconstruction. Basingstoke - Nueva York: Palgrave Macmillan. 
Medina, C. (2007). ¿Qué son los estudios organizacionales? En: Revista Universidad EAFIT, 43(148): 9-24.

Medina, C. (2010). Los estudios organizacionales entre la unidad y la fragmentación. En: Cinta Moebio, (38): 91-109.

Miller, T. (ed.) (2001). A companion to cultural studies. Malden: Blackwell.

Mills, A. \& Mills, J. (2013). CMS: A satirical critique of three narrative histories. En: Organization, 20(1): 117-129.

Mills, A., Simmons, A. \& Mills, J. (2005). Reading organization theory: a critical approach to the study of organizational behaviour and structure (3rd ed.). Aurora: Garamond - London: Global.

Morgan, G. \& Spicer, A. (2009). Critical approaches to organizational change. En: Alvesson, M., Bridgman, T. \& Willmott, H. (eds.) The Oxford handbook of Critical Management Studies (pp. 251-266). Nueva York: Oxford University Press.

Mowday, R. (1997). Celebrating 40 years of the Academy of Management Journal. En: Academy of Management Journal, 40(6): 1400-1413.

Muhr, S., Sørensen, B. \& Vallentin, S. (2010). Ethics and organizational practice: questioning the moral foundations of management. Cheltenham: Edward Elgar.

Nauert, C. (2006). Humanism and the culture of renaissance Europe (2nd ed.). Cambridge: Cambridge University Press.

Nuccetelli, S., Schutte, O. \& Bueno, O. (eds.) (2010). A companion to Latin American philosophy. Malden: Wiley-Blackwell.

Parker, M. (2001). Fucking management: queer, theory and reflexivity. En : Ephemera: Theory \& Politics in Organization, 1(1): 36-53.

Parker, M. (2002a). Against management: organization in the age of managerialism. Cambridge: Polity.

Parker, M. (ed.). (2002b). Utopia and organization. Oxford - Malden: Blackwell Pub.

Parker, M. \& Thomas, R. (2011). What is a critical journal? En: Organization, 18(4): 419-427.

Parker, M., Fournier, V. \& Reedy, P. (2007). The Dictionary of alternatives: utopianism and organisation. Londres - Nueva York: Zed Books.

Perret, V. (2009). Quand le changement devient soluble ou l'idéologie managériale du changement organisationnel. En: Golsorkhi, D., Huault, I. \& Leca, B. (eds.) Les études critiques en management : une perspective francaise (pp. 209-231). Quebec: Presses de l'Université Laval.

Perrow, C. (1972). Complex organizations: a critical essay. Glenview, Ill.,: Scott.

Perrow, C. (1986). Complex organizations: a critical essay (3rd ed.). Nueva York: Random House.

Pesqueux, Y. (2009). Une critique du knowledge management. En: Golsorkhi, D., Huault, I. \& Leca, B. (eds.) Les études critiques en management: une perspective francaise (pp. 261-378). Quebec: Presses de l'Université Laval.

Petit, V. (2009). Les habits neufs du pouvoir. En: Golsorkhi, D., Huault, I. \& Leca, B. (eds.) Les études critiques en management : une perspective francaise (pp. 281-303). Quebec: Presses de l'Université Laval.

Phillips, N. (2006). The adolescence of critical management studies?: a postscript to Clegg, Kornberger, Carter and Rhodes. En: Management Learning, 37(1): 29-31.

Phillips, N. \& Dar, S. (2009). Strategy. En: Alvesson, M., Bridgman, T. \& Willmott, H. (eds.) The Oxford handbook of Critical Management Studies (pp. 414-432). Nueva York: Oxford University Press.
Pichault, F. (2011). Critique de la gestion du changement. En: Taskin, L. \& De Nanteuil, M. (eds.) Perspectives critiques en management: pour une gestion citoyenne (pp. 97-119). Bruselas: De Boeck.

Pierson, F. (1959). The education of American businessmen: a study of university-college programs in business administration. Nueva York: McGraw-Hill.

Prasad, A. (2003a). Postcolonial theory and organizational analysis: a critical engagement. Nueva York: Palgrave Macmillan.

Prasad, A. (ed.) (2003b). Postcolonial theory and organizational analysis: a critical engagement. Nueva York: Palgrave Macmillan.

Prasad, A. (ed.) (2012). Against the grain: advances in post-colonial organization studies. Malmö: Liber - Copenhagen Business School Press.

Prasad, P. (2005). Crafting qualitative research: working in the postpositivist traditions. Armonk: M.E. Sharpe.

Rabassó, C. \& Rabassó, F. (2009). Une approche «chomskyenne» critique et inorthodoxe de la formation au management responsable dans les milieux d'affaires «transculturels» et technologiques. En : Golsorkhi, D., Huault, I. \& Leca, B. (eds.) Les études critiques en management : une perspective francaise (pp. 379-406). Quebec: Presses de l'Université Laval.

Rainelli-Le Montagner, H. (2009). La nouvelle finance est-elle une finance critique? En: Golsorkhi, D., Huault, I. \& Leca, B. (eds.) Les études critiques en management: une perspective francaise (pp. 185-206). Quebec: Presses de l'Université Laval.

Ramirez, C. (2009). Laudit: critique d'une pratique «critique». En: Golsorkhi, D., Huault, I. \& Leca, B. (eds.) Les études critiques en management: une perspective francaise (pp. 261-279). Quebec: Presses de l'Université Laval.

Reynolds, M. \& Vince, R. (2004). Critical management education and action-based learning: synergies and contradictions. En: Academy of Management Learning \& Education, 3(4): 442-456.

Rhodes, C. (2002). Text, plurality and organisational knowledge/I like to write about organisations. En: Ephemera: Theory \& Politics in Organization, 2(2): 98-118.

Roscoe, P. \& Chillas, S. (2013). The state of affairs: critical performativity and the online dating industry. En: Organization, Online First.

Rowlinson, M. \& Carter, C. (2002). Foucault and history in organization studies. En: Organization, 9(4): 527-547.

Rowlinson, M. \& Hassard, J. (2011). How come the critters came to be teaching in business schools? Contradictions in the institutionalization of critical management studies. En: Organization, 18(5): 673-689.

Saavedra, J. (2006). La administración y el origen de la concepción instrumental del hombre en la sociedad moderna. En: Universidad \& Empresa, 8(11): 237-262.

Saavedra, J. (2009). Descubriendo el lado oscuro de la gestión: los Critical Management Studies o una nueva forma de abordar los fenómenos organizacionales. En: Revista Facultad de Ciencias Económicas: Universidad Militar Nueva Granada, 17(2): 45-60.

Saavedra, J., Sanabria, M. \& Smida, A. (2013). De la influencia al poder: elementos para una mirada foucaultiana al Liderazgo. En: Innovar, 23(50): 17-34.

Sanabria, M. (2006). El modelo ecuménico para la comprensión organizacional: una propuesta teórica favorable a la comprensión del sistema cognoscitivo propio de la administración y de su construcción como disciplina. En: Universidad \& Empresa, 8(11): 182-236. 


\section{LOS ESTUDIOS CRIITICOS EN ADMINISTRACIÓN: ORIGEN, EVOLUCIÓN Y POSIBILIDADES DE APORTE AL DESARROLLO DEL CAMPO DE LOS ESTUDIOS ORGANIZACIONALES EN AMÉRICA LATINA}

Sanabria, M. (2014). Réévaluation de l'approche cognitive du changement stratégique. Une étude des mutations des facultés de management colombiennes (2007-2012). Tesis de doctorado Summa Cum Laude en Sciences de Gestion. Caen, Francia: Université de Caen, Institut d'Administration des Entreprises (IAE), NIMEC.

Sanabria, M., Saavedra, J. \& Smida, A. (2014a). Los estudios organizacionales ('organization studies'): fundamentos, evolución y estado actual del campo. Bogotá: Escuela de Administración, Editorial Universidad del Rosario.

Sanabria, M., Saavedra, J. \& Smida, A. (2014b). La construcción de sentido de los investigadores en gestión en Colombia acerca de su campo de conocimiento. En: Innovar, 24(54): 7-25.

Scherer, A. (2003). Modes of explanation in organization theory. En: Tsoukas, H. \& Knudsen, C. (eds.) The Oxford handbook of Organization Theory (pp. 310-344). Oxford - Nueva York: Oxford University Press.

Scherer, A. (2009). Critical theory and its contribution to critical management studies. En: Alvesson, M., Bridgman, T. \& Willmott, H. (eds.) The Oxford handbook of Critical Management Studies (pp. 29-51). Nueva York: Oxford University Press.

Schminke, M. \& Mitchell, M. (2003). From the Editors. In the beginning... . En: Academy of Management Journal, 46(3): 279-282.

Schrift, A. (ed.) (2010). The history of continental philosophy (Vol. 6. Poststructuralism and critical theory's second generation). Durham: Acumen.

Sennett, R. (1998). The corrosion of character: the personal consequences of work in the new capitalism. Nueva York: Norton.

Shenhav, Y. (2003). The historical and epistemological foundations of organization theory: fusing sociological theory with engineering discourse. En: Tsoukas, H. \& Knudsen, C. (eds.) The Oxford Handbook of Organization Theory (pp. 183-209). Oxford - Nueva York: Oxford University Press.

Silverman, D. (1968). Formal organizations or industrial sociology: towards a social action analysis of organizations. En: Sociology, 2(2): 221-238.

Silverman, D. (1970). The theory of organisations: a sociological framework. Londres: Heinemann Educational.

Skålén, P., Fellesson, M. \& Fougère, M. (2008). Marketing discourse: a critical perspective. Londres: Routledge.

Smith, W. (2008). Critical Management Studies: accountability and authenticity. En: Critical Sociology, 34(1): 15-28.

Sotirin, P. \& Tyrell, S. (1998). Wondering about critical management: a review of and commentary on selected texts. En: Management Communication Quarterly (McQ), 12(2): 303-336.

Spicer, A. \& Böhm, S. (2007). Moving management: theorizing struggles against the hegemony of management. En: Organization Studies, 28(11): 1667-1698.

Spicer, A., Alvesson, M. \& Kärreman, D. (2009). Critical performativity: the unfinished business of critical management studies. En: Human Relations, 62(4): 537-560.

Starbuck, W. (2003). The origins of organization theory. En: Tsoukas, H. \& Knudsen, C. (eds.) The Oxford handbook of Organization Theory (pp. 143-182). Oxford - Nueva York: Oxford University Press.

Steinberg, S. \& Cannella, G. (eds.) (2012). Critical qualitative research reader. Nueva York: Peter Lang.

Steyaert, C. \& Janssens, M. (2013). Multilingual scholarship and the paradox of translation and language in management and organization studies. En: Organization, 20(1): 131-142.
Stoecker, R., Tryon, E. \& Hilgendorf, A. (eds.) (2009). The unheard voices: community organizations and service learning. Philadelphia: Temple University Press.

Tadajewski, M. \& Brownlie, D. (eds.) (2008). Critical marketing: contemporary issues in marketing. Hoboken: Wiley.

Tadajewski, M. \& Maclaran, P. (eds.) (2009). Critical marketing studies [Three-Volume Set]. Londres: SAGE.

Tadajewski, M., Maclaran, P., Parsons, E. \& Parker, M. (2011a). Introduction: what is critical management studies? En: Key concepts in Critical Management Studies (pp. 1-6). Los Angeles: SAGE.

Tadajewski, M., Maclaran, P., Parsons, E. \& Parker, M. (eds.) (2011b). Key concepts in critical management studies. Los Angeles: SAGE.

Taskin, L. (2011). Entre réalisme et citoyenneté: pour une critique interne aux sciences de gestion. En: Taskin, L. \& De Nanteuil, M. (eds.) Perspectives critiques en management: pour une gestion citoyenne (pp. 29-47). Bruselas: De Boeck.

Taskin, L. \& De Nanteuil, M. (eds.) (2011). Perspectives critiques en management: pour une gestion citoyenne. Bruselas: De Boeck.

Taskin, L. \& Willmott, H. (2008). Introducing critical management studies: key dimensions. En: Gestion 2000, 25(6): 27-38.

Tatli, A. (2012). On the power and poverty of critical (self) reflection in critical management studies: a comment on Ford, Harding and Learmonth. En: British Journal of Management, 23(1): 22-30.

Thomas, R. (2009). Critical management studies on identity: mapping the terrain. En: Alvesson, M., Bridgman, T. \& Willmott, H. (eds.) The Oxford handbook of Critical Management Studies (pp. 166-185). Nueva York: Oxford University Press.

Thompson, P. \& McHugh, D. (2002). Work organisations: a critical introduction (3rd ed.). Basingstoke: Palgrave.

Thompson, P. \& O'Doherty, D. (2009). Perspectives on labor process theory. En: Alvesson, M., Bridgman, T. \& Willmott, H. (eds.) The Oxford Handbook of Critical Management Studies (pp. 99-121). Nueva York: Oxford University Press.

Tietze, S. \& Dick, P. (2013). The victorious english language: hegemonic practices in the management academy. En : Journal of Management Inquiry, 22(1): 122-134.

Townley, B. (1993). Foucault, power/knowledge, and its relevance for human resource management. En: Academy of Management Review, 18(3): 518-545.

Townley, B. (2008). Reason's neglect: rationality and organizing. Oxford: Oxford University Press.

Tyson, L. (2006). Critical theory today: a user-friendly guide (2nd ed.). Nueva York: Routledge.

Veltz, P. (2011). Le management critique, une question de société. En: Taskin, L. \& De Nanteuil, M. (eds.) Perspectives critiques en management : pour une gestion citoyenne (pp. 83-94). Bruselas: De Boeck.

Vergara, S. (2001). A hegemonia americana em estudos organizacionais. En: Revista de Administração Pública, 35(2): 63-77.

Victor, B. \& Stephens, C. (1994). The dark side of the new organizational forms: an editorial essay. En: Organization Science, 5(4): 479-482

Vino, A. (1996). Telling stories, reflecting, learning: Hannah Arendt and organization. En: Studies in Cultures, Organizations and Societies, 2(2): 309-325.

Voronov, M. (2008). Toward engaged critical management studies. En: Organization, 15(6): 939-945.

Walsh, J. \& Weber, K. (2002). The prospects for critical management studies in the American Academy of Management. En: Organization, 9(3): 402-410. 
Warwick's Organizational Behaviour Staff (2001). Organizational studies: critical perspectives on business and management [Four-Volume Set]. Londres: Routledge.

Watson, T. (1994). In search of management: culture, chaos and control in managerial work. Londres - Nueva York: Routledge.

Weick, K. (1969). The social psychology of organizing. Reading: Addison-Wesley Pub. Co.

Westwood, R. \& Clegg, S. (2003). The discourse of organisation studies: dissensus, politics and paradigms. En: Westwood, R. \& Clegg, S. (eds.) Debating organization: Point-counterpoint in organization studies (pp. 1-42). Malden - Oxford: Blackwell.

Wickert, C. \& Schaefer, S. (2014). Towards a progressive understanding of performativity in critical management studies. Human Relations, Online First.

Williams, J. (2005). Understanding poststructuralism. Chesham: Acumen.
Willmott, H. (2003). Organization theory as a critical science? Forms of analysis and 'new organizational forms'. En: Tsoukas, H. \& Knudsen, C. (eds.) The Oxford handbook of organization theory (pp. 88-112). Oxford - Nueva York: Oxford University Press.

Willmott, H. (2009). Commentary - Science as intervention: recasting Weber's moral vision. En: Organization, 16(1): 143-153.

Willmott, H. (2011). Préface. En: Taskin, L. \& De Nanteuil, M. (eds.) Perspectives critiques en management: pour une gestion citoyenne (pp. 11-15). Bruselas: De Boeck.

Wilson, F. (2010). Organizational behaviour and work: a critical introduction (3rd ed.). Oxford: Oxford University Press.

Winter, R. (2011). A call for critical perspectives in qualitative research. En: Forum: Qualitative Social Research, 12(1).

Wood, S. \& Kelly, J. (1978). Towards a critical management science. En: Journal of Management Studies, 15(1): 1-24. 